See discussions, stats, and author profiles for this publication at: https://www.researchgate.net/publication/334686970

\title{
Self-initiated learning reveals memory performance and electrophysiological differences between younger, older and older adults with relative memory impairment
}

Article in European Journal of Neuroscience · July 2019

DOI: $10.1111 /$ ejn. 14530

CITATIONS

READS

0

113

9 authors, including:

Joanne PM Kenney

Trinity College Dublin

24 PUBLICATIONS 370 CITATIONS

SEE PROFILE

Michael Keane

Dublin City University

10 PUBLICATIONS 132 CITATIONS

SEE PROFILE

Richard A P Roche

National University of Ireland, Maynooth

73 PUBLICATIONS 1,527 CITATIONS

SEE PROFILE

Michael J Hogan

National University of Ireland, Galway

206 PUBLICATIONS 2,632 CITATIONS

SEE PROFILE

Some of the authors of this publication are also working on these related projects:

Project The Threat of Algocracy View project

Project brain segmentation View project 
Self-initiated learning reveals memory performance and electrophysiological differences between younger, older and older adults with relative memory impairment

\author{
Joanne P.M. Kenney ${ }^{1} \uparrow$ \\ Christina Ward ${ }^{2}$ \\ Dervla Gallen ${ }^{2}$ \\ Richard A.P. Roche ${ }^{2}$ \\ Paul Dockree ${ }^{1}$ \\ Nicola Hohensee ${ }^{3}$ \\ Clare Cassidy 3 \\ Michael A. Keane ${ }^{4}$ \\ Michael J. Hogan
}

${ }^{1}$ Department of Psychology, Trinity College Institute of Neuroscience, Trinity College

Dublin, Ireland

${ }^{2}$ Department of Psychology, Maynooth University, Co Kildare, Ireland.

${ }^{3}$ Department of Psychology, NUI, Galway, Ireland.

${ }^{4}$ School of Nursing and Human Sciences, Dublin City University, Dublin 9, Ireland

†Corresponding author; email: kenneyj@tcd.ie

Keywords: Event-related potentials; Ageing; Memory; Self-initiated Learning; Old/New 


\begin{abstract}
Older adults display difficulties in encoding and retrieval of information, resulting in poorer memory. This may be due to an inability of older adults to engage elaborative encoding strategies during learning. This study examined behavioural and electrophysiological effects of explicit cues to self-initiate learning during encoding and subsequent recognition of words in younger adults (YA), older control adults (OA) and older adults with relative memory impairment (OD). The task was a variation of the old/new paradigm, some study items were preceded by a cue to learn the word (L) while others by a do not learn cue (X). Behaviourally, YA outperformed OA and OD on the recognition task, with no significant difference between OA and OD. Event-related potentials at encoding revealed enhanced early visual processing (70-140 ms) for L- versus X-words in young and old. Only YA exhibited a greater late posterior positivity (LPP; 200$500 \mathrm{~ms}$ ) for all words during encoding perhaps reflecting superior encoding strategy. During recognition, only YA differentiated L- versus X-words with enhanced frontal P200 (150-250 ms) suggesting impaired early word selection for retrieval in older groups; however, OD had enhanced P200 activity compared to OA during L-word retrieval. The LPP (250-500 ms) was reduced in amplitude for L-words compared to both X- and new words. However, YA showed greater LPP amplitude for all words compared to OA. For older groups, we observed reduced left parietal hemispheric asymmetry apparent in YA during encoding and recognition, especially for OD. Findings are interpreted in the light of models of compensation and dedifferentiation associated with age-related changes in memory function.
\end{abstract}


SELF-INITIATED LEARNING, AGING, AND EVENT-RELATED POTENTIALS 
SELF-INITIATED LEARNING, AGING, AND EVENT-RELATED POTENTIALS

\section{Introduction}

Age-related cognitive decline is a cause for increasing health concerns (Bishop, Lu, \& Yankner, 2010; Dimitrova et al., 2016), and discerning the key risk factors that are indicative of neurodegenerative disease is an important undertaking (Stoub, DetoledoMorrell, \& Dickerson, 2014). Increased life expectancy rates have seemingly resulted in an increased prevalence of neurological illnesses such as dementia; however, it is important to note that there is a great variability in the degree to which memory is affected by age (Dockree, Brennan, O'Sullivan, Robertson, \& O'Connell, 2015). Cognitive decline has been well documented and appears to be related to functional alterations in neural activity (O'Hora et al., 2013; Puccioni \& Vallesi, 2012) and declines in higher order cognitive systems (Salthouse, 2011) such as executive functioning (Dimitrova et al., 2016). As a result of this decline in both the encoding and retrieval of information, older adults appear to have more difficulty than young adults when it comes to remembering studied information (Craik \& Rose, 2012; Kirchhoff, Anderson, Barch, \& Jacoby, 2012). Research suggests that older adults are less inclined than younger adults to engage in elaborative strategies (such as sentence generation or visual imagery; Hertzog, Mcguire, Horhota, \& Jopp, 2010) in order to deliberately encode visually presented words, which results in difficulties in memory retrieval (Craik \& Byrd, 1982; Hertzog et al., 2010; NavehBenjamin, Brav, \& Levy, 2007; O'Hora et al., 2013).

Self-initiated learning is distinct from both implicit learning, which refers to the passive learning of complex information without any awareness of doing so, and explicit learning, which refers to the active process of seeking out structure in order to learn new information 
SELF-INITIATED LEARNING, AGING, AND EVENT-RELATED POTENTIALS

(DeKeyser, 2008). Several component control processes at encoding and retrieval are important for successful memory performance, such as organising information, engaging in elaborate rehearsal, selecting cues for strategic search and monitoring search outputs (Unsworth, 2009). Many of these component processes involved in encoding and retrieval require, what Craik (1986) and Craik, Routh, and Broadbent (1983) has termed, selfinitiated processing (SIP). SIP relies on self-generated cues and endogenous control of memory. Degradation of SIP with age has been hypothesised as older adults are particularly impaired compared to younger adults where there is minimal environmental support for retrieval (e.g. contextual cues, reminders; Craik, 1986; Craik et al., 1983). In the absence of environmental support, more conscious effort and strategic control of memory via frontal-mediated cognitive control are required for successful memory performance. Tasks that present a cue at encoding and retrieval such as recognition tasks require more SIP than procedural or indirect implicit memory tasks, but less SIP compared to tasks with no cues such as free recall, which requires copious self-initiated processing (Unsworth, 2009). Selfinitiated processing or intentional learning appears to enable the re-creation of an event in one's memory without the guidance of external cues (Einstein, McDaniel, Richardson, Guynn, \& Cunfer, 1995), but healthy older adults and those in the early stages of Alzheimer's disease (AD) have been found to have impaired ability to carry out this process (Hogan et al., 2006).

Neuroimaging studies have consistently highlighted the medial superior frontal, left middle and inferior frontal areas, bilateral orbitofrontal cortex and left lateral temporal regions as the route of self-initiated encoding strategies in young adults (Buckner, 2004; Kirchhoff \& Buckner, 2006; Matsui et al., 2008; Puccioni \& Vallesi, 2012; Rizio \& Dennis, 2014). The 
SELF-INITIATED LEARNING, AGING, AND EVENT-RELATED POTENTIALS

role of the left lateral prefrontal cortex has been consistently identified to be involved in attempts of encoding of to-be-remembered words (Wierzba et al., 2018). During an fMRI task where young adults were instructed to remember or forget words, Wierzba et al. (2018) found the triangular part of the left inferior frontal gyrus, as well as the left middle and superior frontal gyrus to be more active when participants were instructed to remember, with these regions suggested to regulate the activity of the hippocampus. Kirchhoff et al. (2012) propose that these regions may also support older adults in selfinitiated learning, emphasising that episodic memory training using semantic encoding strategies appeared to increase activity in regions such as the medial superior frontal gyrus (SFG). Specifically, training-related changes were clearly found in the medial superior frontal, left middle frontal/precentral, left inferior frontal and left lateral temporal cortices. However, due to low signal in certain regions such as the orbitofrontal cortex, the full effect of strategy training on brain activity remains unknown. In contrast, the right lateral prefrontal cortex has been shown to be engaged in inhibition or suppression of memory traces (Wierzba et al., 2018), with the right middle frontal gyrus and right superior frontal gyrus shown to be more active when instructions to forget words were presented. Research has demonstrated that during memory inhibition/suppression, the right lateral PFC areas regulate activity of the hippocampus, but may also belong to multiple interacting regions, such as the frontoparietal control network or the central executive network which is involved in cognitive control (Bressler \& Menon, 2010; Erika-Florence, Leech, \& Hampshire, 2014; Friedman \& Miyake, 2017; Hampshire \& Sharp, 2015).

Few studies have examined the electrophysiological underpinnings of self-initiated learning or whether changes in the neural processes that support self-initiated learning can 


\section{SELF-INITIATED LEARNING, AGING, AND EVENT-RELATED POTENTIALS}

be used to explain memory performance differences between older adults with intact memory and older adults with relative memory impairment. While a number of electrophysiological studies have pointed to changes in frontal and parietal activations associated with memory decline in older adults (Gutchess, Ieuji, \& Federmeier, 2007; Lawson, Guo, \& Jiang, 2007; Wolk et al., 2009), less is known about the brain changes that moderate self-initiated learning problems in older adults. The use of neuropsychological assessments for identifying early onset of cognitive decline (Ritchie \& Lovestone, 2002), and their association with age-related memory decline, is limited in its validity, and there is a need for biomarkers with greater accuracy, such as electrophysiological markers, to enable early diagnosis of cognitive and memory decline (Hogan, Kilmartin, Keane, \& Collins, 2012). The electroencephalogram (EEG) has been shown to possess valuable diagnostic information for cognitive decline in Alzheimer's disease $(\mathrm{AD})$, and a number of markers have been identified such as reduced alpha and beta power (Li, Nguyen, Potter, \& Zhang, 2019). With respect to event-related potentials, the late posterior positivity (LPP) has been identified as an index for strategic encoding operations in young and older brains. The LPP, which is dominant over parietal scalp, shares similar properties to the P3b component (typically 300-600 ms poststimulus) which is evoked during target detection tasks (Ford et al., 1994) with both differentiating key target-relevant information. The P3b likely arises from widely distributed frontotemporoparietal networks, involving posterior regions such as the temporal/hippocampus regions but also with contributions from frontal top-down areas such as the right dorsolateral prefrontal cortex (O'Connell et al., 2012; Polich, 2007). 


\section{SELF-INITIATED LEARNING, AGING, AND EVENT-RELATED POTENTIALS}

Craik and Rose (2012) proposed that age-related memory decline during encoding is attributed to a reduction in the depth and elaboration of the initial encoding processes and the ability to self-initiate these encoding processes seems to play a determining role in the dynamics of the episodic memory system as a whole (Hogan et al., 2006). The "Production Deficiency" hypothesis indicates that, when compared with younger adults, older adults are less likely to engage in these self-initiated elaborative encoding strategies (Craik \& Byrd, 1982). In fact, findings demonstrate that older adults are significantly more likely to abstain from using any encoding strategies at all during intentional learning (Perfect \& Dasgupta, 1997). Anatomically, the frontal cortices have been implicated in the ability to self-initiate with Alexander, Stuss, and Gillingham (2009), reporting that a group of older adults with frontal lesions appeared to use self-initiated encoding even less regularly than healthy older controls (Alexander et al., 2009). In addition, a substantial body of research has shown that successful encoding depends also on the neural activity occurring a second or so before presentation of a to-be-remembered item (Addante, de Chastelaine, \& Rugg, 2015; De Chastelaine \& Rugg, 2015). Theta oscillations (4-8 Hz) have been shown to play an important part in memory, whereby prestimulus theta activity was found to be associated with more effective encoding in younger and also older adults (Addante, Watrous, Yonelinas, Ekstrom, \& Ranganath, 2011; Strunk \& Duarte, 2019), indicating that this prestimulus theta activity is relatively spared with ageing.

Both EEG (Paller \& Wagner, 2002) and fMRI (Addante et al., 2015; Wagner, Koutstaal, \& Schacter, 1999; Wierzba et al., 2018) studies have demonstrated that activity levels in the frontal cortex linked to stimulus encoding are predictive of whether or not a particular item will be remembered. It is postulated that a decrease in self-initiated learning may be 


\section{SELF-INITIATED LEARNING, AGING, AND EVENT-RELATED POTENTIALS}

due to older adults under-recruiting the frontal cortex during encoding (Logan, Sanders, Snyder, Morris, \& Buckner, 2002; Vallesi, McIntosh, \& Stuss, 2009), which affects memory retrieval (Kirchhoff et al., 2012). This may also be related to the fact that frontal lobes in older adults are particularly vulnerable to reductions in white matter, which are associated with memory decline (Gunning-Dixon, Brickman, Cheng, \& Alexopoulos, 2009). Young adults appear to utilise more discrete areas of the brain, integrating these regions in order to execute tasks (Bishop et al., 2010).

Older adults who demonstrate de-localised activity also tend to perform better than those who do not, consistent with evidence that this may be a compensatory response (Cabeza, Anderson, Locantore, \& Mcintosh, 2002). Notably, young adults appear to employ parietal and occipital regions for successful encoding strategies, whereas ageing is associated with a decline in activity in these areas (Dennis \& Cabeza, 2008). Functional imaging (Dennis \& Cabeza, 2008) and EEG studies (Osorio, Fay, Pouthas, \& Ballesteros, 2010) also suggest a posterior-anterior shift in ageing (PASA), in that older adults compensate for declining parieto-occipital activation by utilising compensatory frontal sites in addition to parietooccipital sites to achieve the desired performance on memory tasks. Recent brain-wide graph theoretic analysis of functional networks has shown that older adults have reduced modular organisation of brain networks compared to younger adults and these networkwide indices of functional connectivity may underlie age-related functional dedifferentiation (Iordan et al., 2018) and predict cognitive decline (Grady, Sarraf, Saverino, \& Campbell, 2016). However, according to the scaffolding theory of ageing and cognition (STAC; Park \& Reuter-Lorenz, 2009; Reuter-Lorenz \& Park, 2014) in the face of these losses of modularity and local efficiency with age, there is the potential for 
SELF-INITIATED LEARNING, AGING, AND EVENT-RELATED POTENTIALS

compensatory scaffolding to recalibrate declining neural systems (Naik, Banerjee, Bapi, Deco, \& Roy, 2017) via engagement of additional neural circuitry. Evidence of greater activation in frontal or parietal regions or greater bilateral brain activity may be indicative of compensatory scaffolding across multiple cognitive domains including memory (see Spreng, Stevens, Chamberlain, Gilmore, \& Schacter, 2010, for review).

Although the abovementioned network-wide indices derived from fMRI have been useful to understand positive and negative changes with age, the high temporal resolution of EEG offers a direct task-related examination of the discrete neurocognitive processes that unfold during encoding and retrieval. Hogan et al. (2006) designed a paradigm called the "learn/no-learn" task, which involves presenting participants with a set of words individually on a computer screen, some of which are preceded by a cue to learn (L) and some of which are preceded by a "do not learn" cue (X). Participants were then presented with another set of words, some of which they had been asked to learn at the time of encoding and were asked if they had seen the word before. Hogan and colleagues found that attempts by patients with $\mathrm{AD}$ to self-initiate learning were ineffective, with no difference in their memory for X-words and L-words, and although older controls remembered more L-words in comparison with X-words, the benefit of a learning cue was significantly greater in the younger control group when compared to older controls. In a similar study, O'Hora et al. (2013) implemented a task on younger, older and cognitively impaired adults, recording EEG activity during the encoding of "to-be-learned" and "tobe-ignored" words. In the light of previous evidence that EEG entropy illustrates great disparity across age, context (Hogan et al., 2012) and individual ability (Richman \& Moorman, 2000), differential task sensitivity was recorded across the frontal, temporal and 


\section{SELF-INITIATED LEARNING, AGING, AND EVENT-RELATED POTENTIALS}

parietal lobes. During encoding, task sensitivity of frontal EEG predicted later retrieval of to-be-learned stimuli, supporting findings that frontal brain activity during encoding facilitates retrieval. The older adults with cognitive decline exhibited a different pattern of entropy during encoding from the control group, while entropy was lower during the learn task than the no-learn task for the control group; in the old declined group, entropy was lower during the no-learn task. However, it was noted that the cognitively impaired older adults did not perform significantly worse than the older control group, indicating that retrieval may have been facilitated by some compensatory means.

The current study utilised this learn/no-learn task in order to examine behavioural and electrophysiological effects of cues to self-initiate learning on the encoding and subsequent recognition of visually presented words. We utilised a 64-channel ERP array to investigate event-related potential (ERP) waveform components during the task in three groups: younger adults (YA), older control adults (OA) and older adults with relative memory impairment (adults who performed $1 S D$ below age- and education-matched peers on standardised tests of memory; OD). Behaviourally, superior performance, reflected in greater accuracy and faster response times, was predicted for the young group, with poorer performance anticipated in the older groups, particularly the older relatively impaired group. In terms of ERPs, we focus our analysis on the encoding and recognition phase of the task. At encoding, we predict that both young and older participants will show normal orienting to predictive cue information indicative of intact early visual processing of the occipital P100 response. However, we hypothesise that differences in effortful selfinitiated or strategic encoding of words as a function of age will be indexed by age-related amplitude differences in later ERP components (e.g. the late posterior positivity, which is 
SELF-INITIATED LEARNING, AGING, AND EVENT-RELATED POTENTIALS

associated with greater elaborative and strategic encoding and is considered to be a correlate of recollection-related processes discriminating old from new words; Linden, 2005; Tsivilis et al., 2015). At recognition, it is known that maintaining a retrieval mode necessitates an interaction between frontal brain regions involved in selection of posterior regions involved in task-relevant perceptual processing (Bourisly \& Shuaib, 2018). We investigate age differences in frontal engagement indexed by frontal P200, which has been linked to an index of memory strength (Gonsalves, Kahn, Curran, Norman, \& Wagner, 2005; Tsivilis, Otten, \& Rugg, 2001) and also linked to the intentional retrieval of visually specific memory processes (Curran \& Dien, 2003; Schaefer, Pottage, \& Rickart, 2011; Voss, Schendan, \& Paller, 2010) and the late posterior positivity (LPP) seen in parietal old/new studies and understood to be associated with recollective processing during retrieval. In general, we predict that the younger group will show a typical pattern of left lateralisation of ERP componentry over posterior regions, while a more bilateral distribution would be predicted for the two older groups, consistent with the STAC model (Reuter-Lorenz et al., 2000; Reuter-Lorenz \& Park, 2014) or pattern of dedifferentiation.

\section{Method}

\subsection{Participants}

A total of 22 young adults (YA), 19 older adult controls (OA) and 20 older adults with relative memory impairment $(\mathrm{OD} ;$ mean age $=21.68,73.6$ and 73.3 years; education $=16.14,13.15$ and 12.5 years, respectively) were recruited with informed 
consent. Older adults were recruited from the National University of Ireland Galway (NUIG) database of well elderly. Younger adults were students studying psychology at the same institute. All participants received a comprehensive medical and neuropsychological assessment (Hogan, Swanwick, Kaiser, \& Rowan, 2003; Swanwick et al., 1996). Individuals were excluded if they were smokers or if they were taking medication with CNS effects. Also excluded were left-handed people, those who did not speak English as a first language, and those with epilepsy, diabetes, or a history of head injury, strokes or TIAs. Those with a history of depression, but who were currently not affected were considered for inclusion, as were those who had thyroid problems or hypertension which had been stably controlled for 3 months or more. Neuropsychological screening tests included the following: the Mini-Mental State Examination (MMSE; Folstein, Folstein, \& McHugh, 1975), the national adult reading test (NART; Nelson, 1982), the word reading subtest of the Wide Ranging Achievement Test (WRAT; Jastak \& Jastak, 1978) and three subscales of the Wechsler Memory Scale (WMS; Logical Memory, Faces and Visual Reproduction; Wechsler, 1987). Other tests in the screening but not included in the current analyses included the hospital anxiety depression scale (HADS; Zigmond \& Snaitth, 1983), a memory self-rating scale and a test of fluency (animal naming). To allocate older adults into the "normal" or "control" group (OA) and the "relatively memory impairment" group (OD), scores on these WMS subscales were used. Specifically, scores on these indices were compared to scores on the NART. Scores on the NART provide an estimation of premorbid IQ (Baltes, 1997). Older adults were placed in the OA group if their WMS memory score was not more than $1 S D$ lower than their NART score; allocation to the OD group was made if the memory score was $1 S D$ or more below the NART score. 
SELF-INITIATED LEARNING, AGING, AND EVENT-RELATED POTENTIALS

This system of measurement allowed for the identification of those older adults whose memory function may be in very early stages of relative memory impairment compared to age- and education-matched peers.

\subsection{Procedure}

Medical/neuropsychological and electrophysiological/information processing assessments took place on two separate days. Upon first arrival to the testing room, participants completed the paper and pencil and memory tests. During the second session, participants were prepared for the EEG task and provided with an opportunity to practise using the computer interface prior to the task.

\subsection{EEG Task: Learn/no-Learn Task}

During encoding, 120 words were presented to participants for 1,500 $\mathrm{ms}$ in white font on a grey background, above a yellow fixation crosshair. An "L"- or "X"-cue, which lasted $200 \mathrm{~ms}$, was presented 1,200 ms before each word. This cue prompted the participant to either learn ("L") or not learn ("X") the word that followed. Six buffer words were presented at the beginning of the task in order to remove any possibility of a primacy effect. Participants were instructed to keep their eyes fixed on the yellow crosshair at all times during the task, to prevent disengagement when the "X"-words were presented. Participants were not required to make any responses. Words were a mix of monosyllabic and polysyllabic words, for example magazine, cotton, tube, custom, hazard, pint and fable. The average word length was 5 (maximum $=9$; minimum $=4)$, the average number of phenomes was 4 (maximum $=7$; minimum $=2)$, and the average number of syllables was $1($ maximum $=3 ;$ minimum $=1)$. 
SELF-INITIATED LEARNING, AGING, AND EVENT-RELATED POTENTIALS

During recognition, participants were again presented with words in white font on a grey background above the yellow fixation crosshair. Again 120 words were presented, of which 40 were "to-be-learned" ("L") words from the encoding phase, 40 were "not-to-be learned" ("X") from the encoding phase, and 40 words were "new" words not presented previously. Words were presented for $500 \mathrm{~ms}$, with an ISI of 3,500 ms between words. Participants made responses on an Ergodex response pad (www.ergodex.com). Upon the presentation of words in the recognition phase, participants were asked to decide whether the word was presented in the encoding phase, regardless of whether it was an "L"-word or an "X"-word. Again, six buffer words were presented at the beginning of this phase.

\subsection{EEG recordings}

Electrophysiological data were recorded in AC mode with a gain of 500 and a band pass of $0.5-100 \mathrm{~Hz}$. The $0.5 \mathrm{~Hz}$ cut-off was implemented as it was deemed highly unlikely that memory-related processing would be seen at that end of the scale, given that the majority of memory-related data seem to occur within theta range. The $\mathrm{A} / \mathrm{D}$ conversion rate was 1,000 Hz. Each participant wore an ActiCAP EEG recording cap connected to the BrainVision EEG recording system (Brain Products, GmbH, München, Germany) for the duration of the task. Scalp potentials were obtained using a 64-channel array with a common reference electrode and an anterior scalp ground (AFz). The electrode array conformed to the International 10-20 System (American Electroencephalographic Society, 1994). Vertical eye movements were recorded with two electrodes placed above and below the left eye, while electrodes at the outer canthus of each eye recorded horizontal movements. Silver/silver chloride $(\mathrm{Ag} / \mathrm{AgCl})$ electrodes were used at all sites. Recording commenced when electrical impedance had been reduced to $<10 \mathrm{kOhms}$. 


\subsection{Electrophysiological data analysis}

In general, the number of bad channels removed was very low. Wherever possible (i.e. where the affected channel was not located at the edge of the montage), bad channels were interpolated. Using BrainVision Analyser (Brain Products, GmbH, München, Germany), these recordings were then subjected to ocular artefact reduction using blink-averaging algorithms to remove artifactual scalp potentials caused by eyeblinks. Trials in which amplitudes exceeded $\pm 100 \mu \mathrm{V}$ at any scalp electrode were automatically rejected. All trials were baseline-corrected using the prestimulus interval as the baseline interval and epoched into single-trial recordings, from $-250 \mathrm{~ms}$ prestimulus to $1,000 \mathrm{~ms}$ poststimulus. Epochs were separated into stimulus category from the encoding phase (L-cue, X-cue, L-word, Xword) and combined to produce grand average waveforms. Incorrect responses and nonresponses during the recognition phase were manually selected from these EEG trials and were excluded from the subsequent analysis. The remaining epochs were separated into stimulus categories (L-word, X-word, new word) and combined to produce grand average waveforms. The grand averages were then exported into the BESA format (.raw file). An overall grand mean waveform was generated for each electrode by collapsing across all conditions. BESA enabled ease of viewing of event-related potential (ERPS) for each electrode and head map for each condition. Visual inspection of the ERPs enabled a suitable time window to be determined for each of the components of interests (P100, P200 and late posterior parietal were the focus of this study). Electrodes were selected based on the location where the centre of activity occurred, evident from the topographical maps. These electrodes were then included in the analysis. 


\subsection{Statistics for behavioural data}

Memory accuracy (hit rate - false alarm rate) and reaction time for correct responses were assessed. Mixed factorial $(3 \times 3)$ ANOVAs were conducted for memory accuracy and reaction time with group: young adults (YA), older control adults (OA) and older adults with relative memory impairment (OD) as the between-subjects and stimulus (L-word, Xword, new word) as within-subjects factors. The hit rate and false alarm rate were also assessed using a similar model, and results are included in Appendix S1: Section 1 and 2. Hits were defined as the number of times a participant correctly identified an "old" word as one they had seen before, whereas false alarms were defined as the number of times a participant incorrectly identified a "new" word as an "old" word. Hit rate and false alarm rate were calculated as a percentage of total stimuli per condition (i.e. 40). Normality for each variable was assessed by inspecting Q-Q plots, and any values $>3 S D$ from the mean were considered outliers and removed. Post hoc pairwise comparisons were Bonferroniadjusted (SPSS Bonferroni-adjusted $p$-values are quoted; alpha $=.05$ ).

\subsection{Statistics for electrophysiological data}

Mixed factorial analysis of variance (ANOVA) was used to examine ERP differences between the three groups (young, older control adult and older adults with relative memory impairment), during both encoding and recognition. An overall grand mean waveform for each condition at each electrode was obtained, and visual inspection identified the latency windows and electrode sites of interest. Certain electrode sites were chosen due to maximal component activity in this area, and mean amplitude (MA) data for each condition were 
SELF-INITIATED LEARNING, AGING, AND EVENT-RELATED POTENTIALS

extracted from each selected electrode (see Section 3.4.2: Encoding \& section 3.4.3: Recognition for electrode sites). Mean amplitude was based on correct responses only.

The data were entered into SPSS (version 17 for Windows) for statistical analysis. Normality was assessed by inspecting Q-Q plots, and any values $>3 S D$ from the mean were considered outliers and removed. Mixed factorial ANOVAs were conducted for each component (P100, late posterior positivity [LPP]) at the encoding and recognition (P200, LPP) phase. Encoding cue: A $3 \times 2 \times 2$ ANOVA was conducted with group (YA, OA, OD) as the between-subject and stimulus (X-cue, L-cue) and hemisphere (left, right) as withinsubject factors. Encoding word: A $3 \times 2 \times 2$ ANOVA was conducted: Group $\times$ Stimulus $(\mathrm{X}$-word, L-word $) \times$ Hemisphere. Recognition: A $3 \times 3 \times 2$ ANOVA was conducted: Group $\times$ Stimulus $(\mathrm{X}$-word, L-word, new word $) \times$ Hemisphere. Post hoc pairwise comparisons were Bonferroni-adjusted (SPSS Bonferroni-adjusted $p$-values are quoted).

\subsection{Lateralisation index}

A lateralisation index (LI) was calculated for each group (YA, OA, OD) to determine laterality patterns of electrophysiological activity between left and right hemispheres in parietal (LPP) and frontal (P2) regions, for each stimulus (new, L-word, X-word) during recognition. The following formula was used to determine each LI (left mean amplitude (MA) - right MA)/(left MA + right MA; Kenney et al., 2017). For each group, separate correlational analyses were conducted to determine the relationship between the LI of each component and behavioural measures (accuracy and reaction time) during recognition. Results were Bonferroni-adjusted ( $p$-value/number of comparisons per stimuli (3) for each component; alpha $=.05 / 3=.017)$. 


\section{Results}

\subsection{Neuropsychological measures}

The number of years in formal education was significantly longer in the younger group compared with the other two groups $(p<.01$; see Table 1 for means and $S D)$. There was no difference between the three groups on either the NART or WRAT tests of verbal ability. Young adults had higher MMSE scores when compared with the older adults with relative memory impairment $(p<.05)$, but no other differences were observed on this measure. All groups scored above 28 on the MMSE. However, young adults scored higher than both old adult groups on the three subscales of the WMS (Logical Memory IIRecognition; Visual Reproduction-Total Recall and Total Copy score; and Faces I and Faces II $(p<.001)$ for all WMS subtests). Older controls scored significantly higher than the older adults with relative memory impairment on the logical memory subscale and Faces II subtest $(p<.01$; see Table 1$)$. 
Table 1. Demographics and neuropsychological assessment score means and standard deviations (SDs) for the three groups

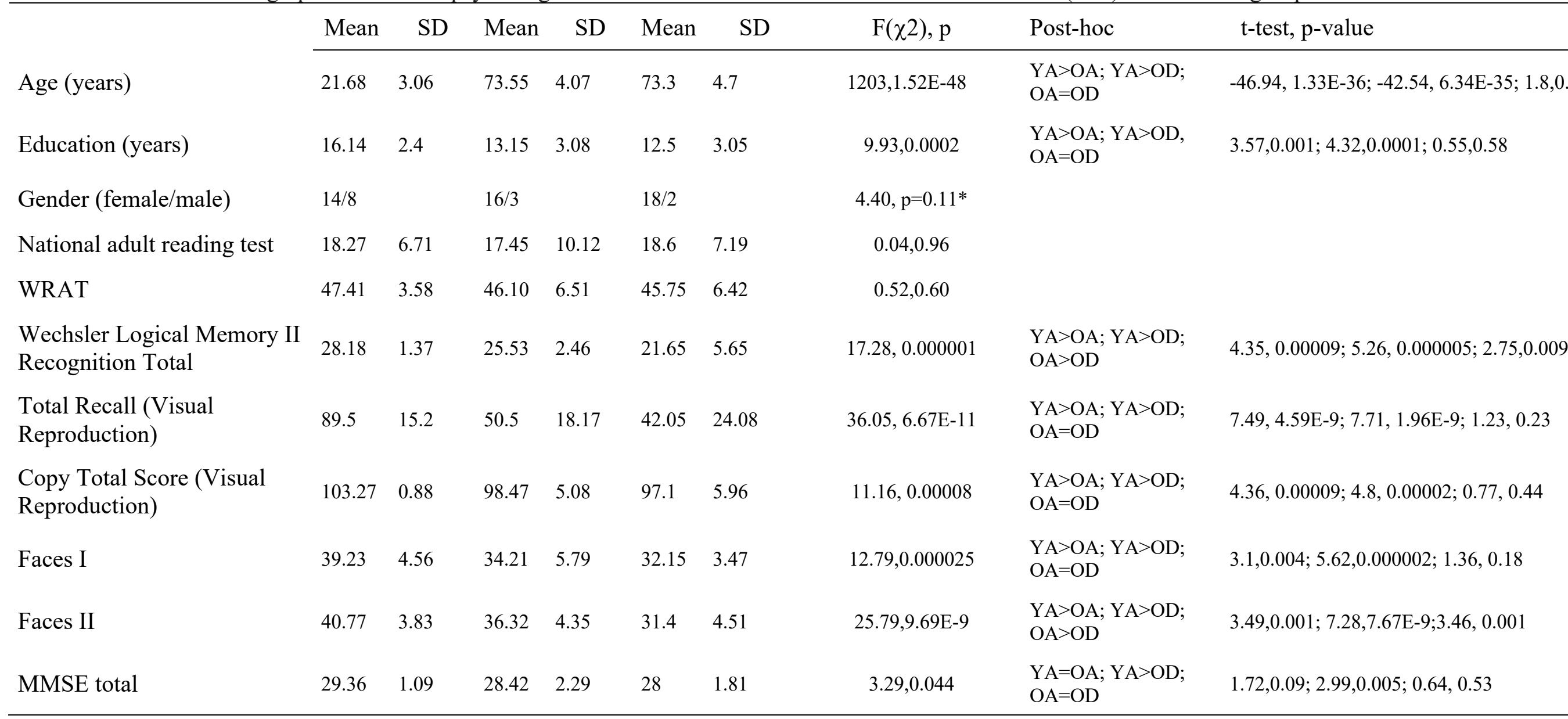

Note: $*=$ due to the small numbers per cell a Fishers Exact Test was conducted to test group differences in gender. YA $=$ younger adults; OA $=$ older control adults; $\mathrm{OD}=$ older adults with relative memory impairment. $\mathrm{SD}=$ standard deviation; 
SELF-INITIATED LEARNING, AGING, AND EVENT-RELATED POTENTIALS

3.2 Behavioural Performance: Recognition Memory Accuracy

The mixed factorial ANOVA revealed a main effect of group, $F_{2,57}=11.55 ; p=.00065$, partial $\eta^{2}=0.29$, with better overall memory accuracy (hits - false alarms) in YA (Mean $(M) \pm$ standard error $(S E)=48.78 \pm 3.92)$ when compared with both OA $(M \pm S E=26.16 \pm 4.24 ; p=.001) \quad$ and $\quad$ OD $\quad(M \pm S E=24.25 \pm 4.11 ; p=.0002)$. The difference between OA and OD was not statistically significant $(p=1.00)$. There was also a main effect of stimulus (sphericity was violated; therefore, Greenhouse-Geissercorrected values were used), $F_{1.3,77.6}=15.28 ; p=.000001$, partial $\eta^{2}=0.21$, with better accuracy for new words $(M \pm S E=51.74 \pm 3.56)$ compared with X-words $(M \pm S E=16.51 \pm 4.89 ; p=8.45 \mathrm{E}-12)$ and L-words $(M \pm S E=30.95 \pm 4.64 ; p=.007)$ There was no significant difference between L-words and X-words $(p=.23)$. The Group $\times$ Stimulus interaction effects were not significant, $F_{2.72,77.6}=0.63 ; p=.59$ (see Figure 1a).

\subsection{Recognition Reaction Times}

The mixed factorial ANOVA revealed a significant a Group $\times$ Stimulus interaction effect (sphericity was violated; therefore, Greenhouse-Geisser corrected values were used), $F_{3.35,95.47}=7.52, p=.00002$, partial $\eta^{2}=0.21$.

\subsubsection{Post hoc pairwise comparison by Group}

For L-words, YA had significantly faster reaction time (RT; $M \pm S E=925.2 \pm 41.19)$ compared to $\quad$ OA $\quad(M \pm S E=1186.17 \pm 44.33 \quad(p=.00019) \quad$ and $\quad$ OD 
SELF-INITIATED LEARNING, AGING, AND EVENT-RELATED POTENTIALS

$(M \pm S E=1088.2 \pm 43.33 ; p=.028)$. For new words, again, YA had faster RTs $(M \pm S E=1022.26 \pm 57.84)$ compared to $\mathrm{OA} \quad(M \pm S E=1516.34 \pm 62.23 ; p=9.58 \mathrm{E}-$ 7) and $\mathrm{OD}(M \pm S E=1391.38 \pm 62.24 ; P=.00007)$. There were no significant differences between the two older adult groups for L-words $(p=.37)$ and new words $(p=.48)$, nor were there any significant group differences for X-words $\left(p_{\text {range }}=.45-1.00\right)$.

\subsubsection{Post hoc pairwise comparison by word type}

YA had significantly faster RT for L-words $(M \pm S E=925.18 \pm 41.19)$ compared to Xwords $(M \pm S E=1108.78 \pm 58.75 ; p=.0004)$. There was no difference between L-words and new words $(M \pm S E=1022.26 \pm 57.84 ; p=.22)$, nor between $\mathrm{X}$-words and new words $(p=.56)$. OA had significantly faster $\mathrm{RT}$ for L-words $(M \pm S E=1186.17 \pm 44.33 ; p=6.14 \mathrm{E}-7) \quad$ and $\quad$ X-words $(M \pm S E=1176.96 \pm 63.22 ; p=.00003) \quad$ compared to new words $(M \pm S E=1516.34 \pm 62.23)$. There was no difference between L-word and $\mathrm{X}$-word $(p=1.00)$. Finally, for the OD, RTs were significantly faster for L-words $(M \pm S E=1088.2 \pm 44.33)$ compared to $\mathrm{X}$-words $(M \pm S E=1233.92 \pm 63.22 ; p=.012)$ and compared to new words $(M \pm S E=1391.38 \pm 62.24 ; p=.000004)$. There was no difference between X-words versus new words ( $p=.86$; see Figure $\underline{1} \mathrm{~b})$. 
A)

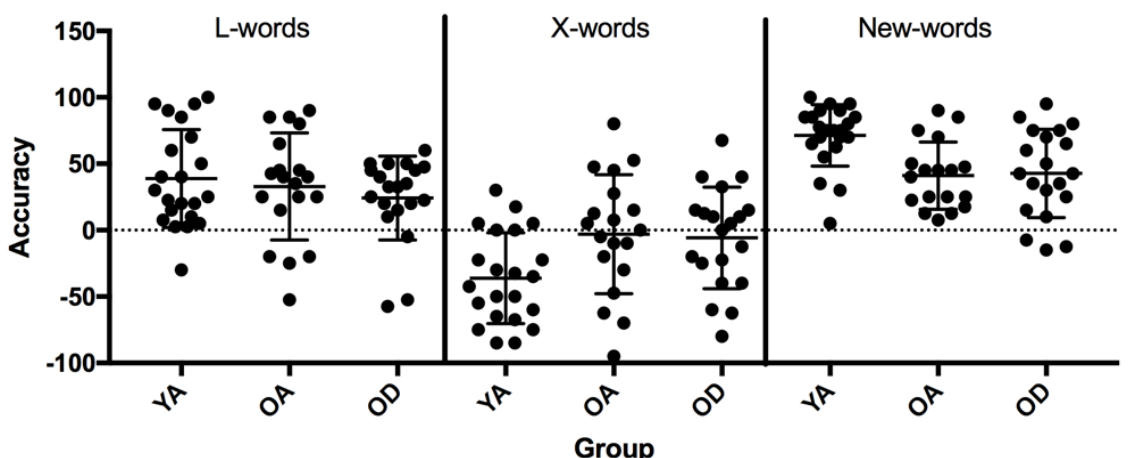

B)

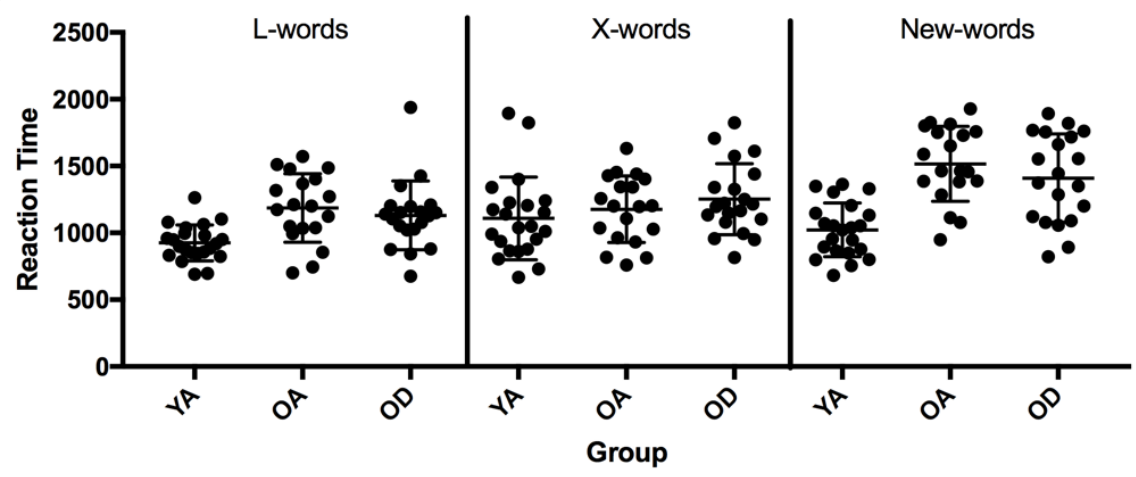

Figure 1

(a) Scatter plots (with mean and IQR) showing recognition memory accuracy (hits-false alarms) for L-words, X-words and new words for young (YA), older control (OA) and older adults with relative memory impairment (OD) adults. (b) Scatter plots (with mean and $\mathrm{IQR}$ ) showing recognition reaction times (RTs) for L-words, X-words and new words for young (YA), older control (OA) and older adults with relative memory impairment (OD) adults

\subsection{Event-related Potentials: Encoding Block}

Visual inspection of the grand mean waveforms (collapsed across all groups and conditions) elicited during the encoding phase indicated the presence of a P100 component (maximal from 70 to $140 \mathrm{~ms}$ ) at bilateral occipitoparietal electrodes PO7 and PO8, 
followed by a late posterior positivity $(200-500 \mathrm{~ms})$ at the same occipitoparietal sites PO7 and PO8 (see Figure 2).

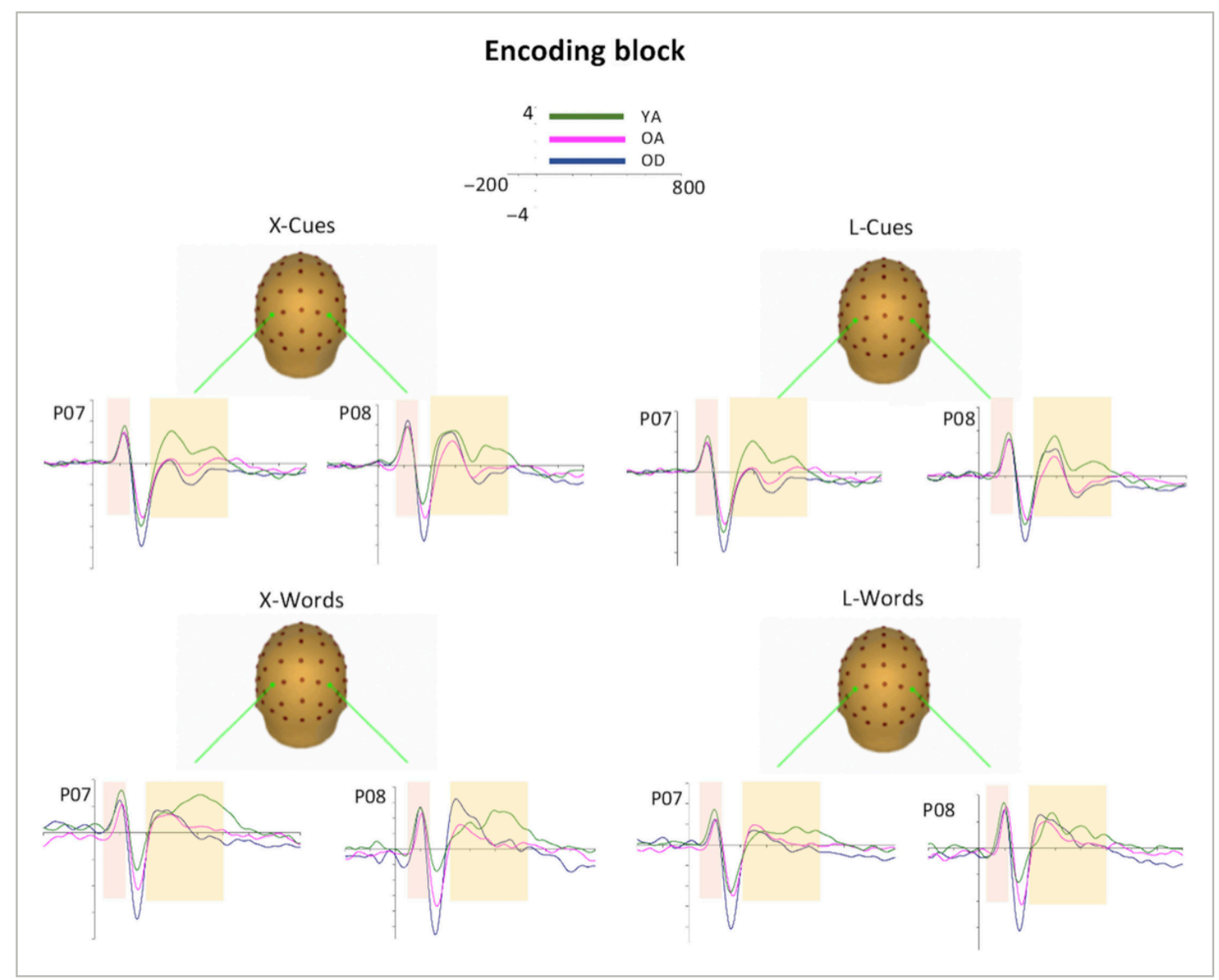

\section{Figure 2}

ERP waveform components (P100 and late posterior positivity) over posterior sites for Lcues, X-cues, L-words and X-words during the encoding block in young adults (YA), older adult controls (OA) and older adults with relative memory impairment (OD) 
SELF-INITIATED LEARNING, AGING, AND EVENT-RELATED POTENTIALS

\section{$\underline{\text { 3.4.1 P100 X-cue versus L-cue }}$}

The mixed factorial ANOVA revealed a significant Group $\times$ Stimulus $\times$ Hemisphere interaction effect $\left(F_{2,55}=3.44, p=.039\right.$, partial $\left.\eta^{2}=0.11\right)$.

Post hoc comparison by hemisphere indicated that for YA, in the left hemisphere there was higher mean amplitude (MA) for $\mathrm{X}$-cue $(M \pm S E=2.93 \pm 0.31)$ compared to L-cue $(M \pm S E=2.41 \pm 0.31 ; p=.037)$, whereas for OD, in the right hemisphere there was higher $\mathrm{MA}$ in $\mathrm{X}$-cue $(M \pm S E=3.22 \pm 0.36)$ relative to L-cue $(M \pm S E=2.20 \pm 0.31 ; p=.001)$. For OA, there was no difference between stimuli in the right or left hemisphere $\left(p_{\text {range }}=.29-.97\right)$.

Post hoc comparison by group also identified that for OD, for X-cues there was higher MA in the right $(M \pm S E=3.22 \pm 0.36)$ compared to the left hemisphere $(M \pm S E=2.47 \pm 0.32 ; p=.034)$. For YA or OA, there was no difference in stimuli between hemispheres $\left(p_{\text {range }}=.11-.81\right)$.

There was also a main effect of stimulus $\left(F_{2,55}=8.36, p=.005\right.$, partial $\left.\eta^{2}=0.13\right)$. There was higher $\mathrm{MA}$ for $\mathrm{X}$-cue $(M \pm S E=2.68 \pm 0.17)$ compared to L-cue $(M \pm S E=2.29 \pm 0.16 ; p=.005)$.

\section{$\underline{\text { 3.3.2 P100 X-word versus L-word }}$}

The mixed factorial ANOVA revealed no significant Group $\times$ Stimulus $\times$ Hemisphere interaction effect $\left(F_{2,55}=0.14, p=.87\right.$, partial $\left.\eta^{2}=0.005\right)$. There was a main effect of stimulus $\left(F_{1,55}=11.13, p=.002\right.$, partial $\left.\eta^{2}=0.17\right)$, whereby there was higher MA for Lword $(M \pm S E=2.68 \pm 0.22)$ compared to X-word $(M \pm S E=2.26 \pm 0.17 ; p=.002)$. 


\subsubsection{Late Posterior Positivity $X$-cue versus L-cue}

There was no significant Group $\times$ Stimulus $\times$ Hemisphere interaction $\left(F_{2,55}=0.99, p=.39\right)$. There was, however, a main effect of group $\left(F_{2,55}=4.11, p=.022\right.$, partial $\left.\eta^{2}=0.13\right)$. YA $(M \pm S E=3.08 \pm 0.23)$ had higher MA compared to OA $(M \pm S E=2.11 \pm 0.24 ; p=.018)$. There was no difference between YA and OD $(M \pm S E=2.64 \pm 0.24 ; p=.58)$ or between OA and OD $(p=.39)$. There was no main effect of stimulus $\left(F_{2,55}=1.43, p=.24\right)$.

\subsubsection{Late Posterior Positivity $X$-word versus L-word}

There was no significant Group $\times$ Stimulus $\times$ Hemisphere interaction $\left(F_{2,55}=0.88, p=.42\right)$. There was however a main effect of group $\left(F_{2,55}=4.52, p=.015\right.$, partial $\left.\eta^{2}=0.14\right)$. YA $(M \pm S E=2.44 \pm 0.18)$ had higher MA compared to OA $(M \pm S E=1.65 \pm 0.19 ; p=.012)$. There was no difference between YA and OD $(M \pm S E=2.12 \pm 0.19 ; p=.25)$ or between OA and OD $(p=.67)$. There was no main effect of stimulus $\left(F_{1,55}=0.08, p=.78\right)$.

\subsection{Recognition Block}

Visual inspection of the grand mean waveforms (collapsed across all groups and conditions) elicited during the recognition phase indicated the presence of an anterior positive P200 component was also identified at bilateral frontal sites (150-250 ms), F1 and 
F2 (new word), and F3 and F4 (L-word), and F7 and F8 (X-word; see Figure 3), and a late positive posterior component (maximal from 250 to $500 \mathrm{~ms}$ ) at bilateral occipitoparietal electrodes PO7 and P2 (L-word), P07 and PO8 (X-word), and P1 and P2 (new word; see Figure 4).

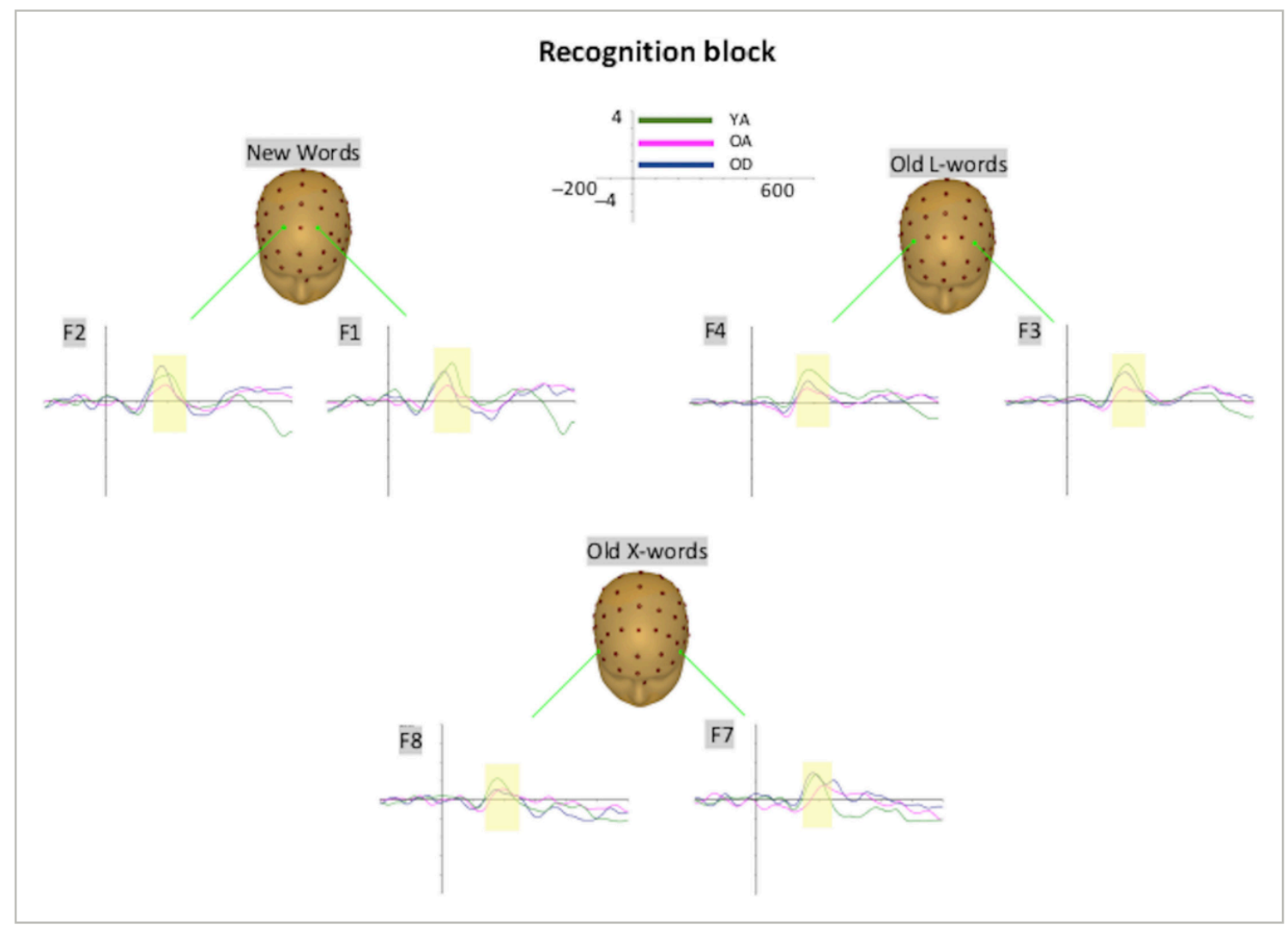

Figure 3

Anterior ERP waveform components for new words, L-words and X-words during the recognition block in young adults (YA), older adult controls (OA) and older adults with relative memory impairment (OD) 


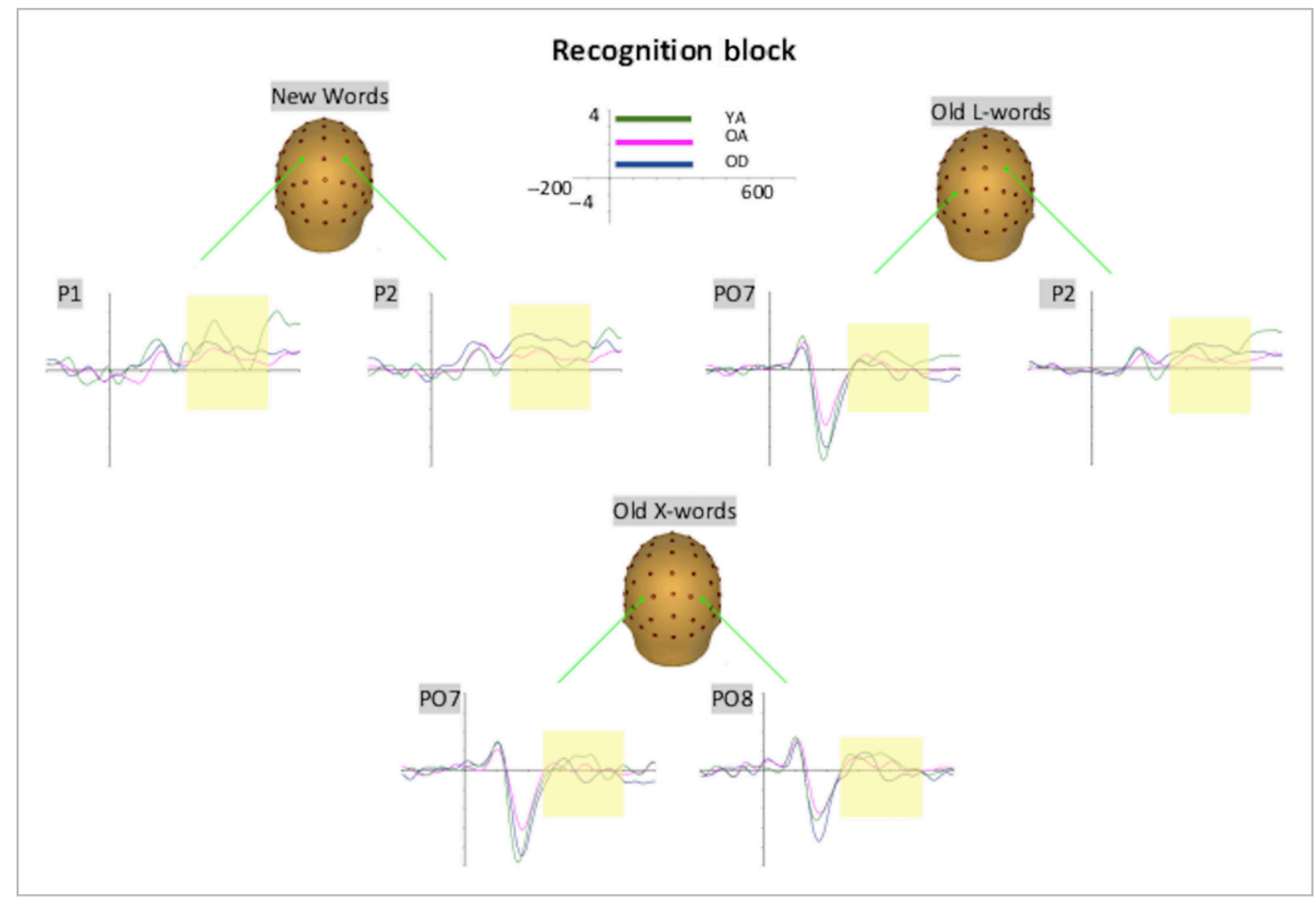

\section{Figure 4}

Late posterior positivity (LPP) waveform components over posterior sites for new words, L-words and $\mathrm{X}$-words during the recognition block in young adults (YA), older adult controls (OA) and older adults with relative memory impairment (OD)

\subsubsection{Frontal P200}

There was no significant Group $\times$ Stimulus $\times$ Hemisphere interaction effect $\left(\mathrm{F}_{3.42,88.09}=0.60, \mathrm{p}=.64\right)$. However, there was a Group $\times$ Stimulus interaction effect $\left(\mathrm{F}_{3.7,97.1}=4.35, \mathrm{p}=.003\right.$, partial $\left.\eta^{2}=0.15\right)$ 


\section{SELF-INITIATED LEARNING, AGING, AND EVENT-RELATED POTENTIALS}

Pairwise comparison by word type revealed that for YA, there was higher MA for new word $(\mathrm{M} \pm \mathrm{SE}=3.33 \pm 0.29)$ compared to $\mathrm{X}$-word $(\mathrm{M} \pm \mathrm{SE}=1.75 \pm 0.22 ; \mathrm{p}=.000005)$, and higher $\mathrm{MA}$ for $\mathrm{L}$-word $(\mathrm{M} \pm \mathrm{SE}=2.83 \pm 0.30)$ compared to $\mathrm{X}$-word $(\mathrm{p}=.00007)$. There was no difference between L-word and new word $(p=.24)$. There was no difference between word types in the OA group $\left(\mathrm{p}_{\text {range }}=.20-1.00\right)$, new word $(\mathrm{M} \pm \mathrm{SE}=2.03 \pm 0.29)$, $\mathrm{L}$-word $(\mathrm{M} \pm \mathrm{SE}=1.52 \pm 0.30)$ and $\mathrm{X}$-word $(\mathrm{M} \pm \mathrm{SE}=1.74 \pm 0.22)$, nor was there any significant difference in the OD group ( $\left.p_{\text {range }}=.14-1.00\right)$, new word $(\mathrm{M} \pm \mathrm{SE}=2.71 \pm 0.29), \quad$ L-word $\quad(\mathrm{M} \pm \mathrm{SE}=2.59 \pm 0.30) \quad$ and $\quad \mathrm{X}$-word $(\mathrm{M} \pm \mathrm{SE}=2.12 \pm 0.22)$.

Pairwise comparison by group revealed that for new words, $\mathrm{YA}(\mathrm{M} \pm \mathrm{SE}=3.33 \pm 0.29)$ had higher $\mathrm{MA}$ than $\mathrm{OA}(\mathrm{M} \pm \mathrm{SE}=2.03 \pm 0.29 ; \mathrm{p}=.007)$. For L-words, YA $(\mathrm{M} \pm \mathrm{SE}=2.83 \pm 0.30)$ had higher $\mathrm{MA}$ than $\mathrm{OA}(\mathrm{M} \pm \mathrm{SE}=1.52 \pm 0.39 ; \mathrm{p}=.010)$ and higher $\mathrm{MA}$ for $\mathrm{OD}(\mathrm{M} \pm \mathrm{SE}=2.59 \pm 0.30)$ compared to $\mathrm{OA}(\mathrm{p}=.046)$. There were no group differences for $\mathrm{X}$-word $\left(\mathrm{p}_{\text {range }}=.74-1.00\right)$. There was also a main effect of stimulus $\left(F_{1.8,97.1}=9.72, p=.00013\right.$, partial $\left.\eta^{2}=0.16\right)$. There was higher mean amplitude for new word $(\mathrm{M} \pm \mathrm{SE}=2.69 \pm 0.16)$ compared to $\mathrm{X}$-word $(\mathrm{M} \pm \mathrm{SE}=1.87 \pm 0.13 ; \mathrm{p}=.00003)$ and higher mean amplitude for $\mathrm{L}$-word $(\mathrm{M} \pm \mathrm{SE}=2.31 \pm 0.18)$ compared to $\mathrm{X}$-word $(p=.005)$. There was no significant difference between new word and L-word $(p=.07)$

There was also a main effect of group $\left(\mathrm{F}_{251}=4.27, \mathrm{p}=.019\right.$, partial $\left.\eta^{2}=0.14\right)$. YA had higher $\mathrm{MA}(\mathrm{M} \pm \mathrm{SE}=2.64 \pm 0.22)$ compared to $\mathrm{OA}(\mathrm{M} \pm \mathrm{SE}=1.76 \pm 0.22 ; \mathrm{p}=.025)$, and OD had higher $\mathrm{MA}(\mathrm{M} \pm \mathrm{SE}=2.47 \pm 0.22)$ than $\mathrm{OA}$, but this did not reach the significance level $(p=.09)$. There was no difference between YA and the OD groups $(p=1.00)$. 
SELF-INITIATED LEARNING, AGING, AND EVENT-RELATED POTENTIALS

\subsubsection{Late posterior positivity}

The mixed factorial ANOVA revealed no significant Group $\times$ Stimulus $\times$ Hemisphere interaction effect $\left(\mathrm{F}_{3.47,90.33}=0.95, \mathrm{p}=.43\right)$. However, there was a Group $\times$ Hemisphere interaction effect $\left(F_{2,52}=9.89, p=.00028\right.$, partial $\left.\eta^{2}=0.28\right)$.

Pairwise comparison by group revealed that in the left hemisphere, YA $(\mathrm{M} \pm \mathrm{SE}=3.51 \pm 0.29)$ had significantly higher mean amplitude than the OA $(\mathrm{M} \pm \mathrm{SE}=2.08 \pm 0.29 ; \mathrm{p}=.004)$ and $\mathrm{OD}(\mathrm{M} \pm \mathrm{SE}=2.48 \pm 0.29 ; \mathrm{p}=.048)$. There was no difference between $\mathrm{OA}$ and $\mathrm{OD}(\mathrm{p}=.99)$. In the right hemisphere, OD $(\mathrm{M} \pm \mathrm{SE}=2.45 \pm 0.22)$ had higher amplitude than $\mathrm{OA}(\mathrm{M} \pm \mathrm{SE}=1.79 \pm 0.22 ; \mathrm{p}=.001)$ There was no difference between $\mathrm{YA}(\mathrm{M} \pm \mathrm{SE}=2.45 \pm 0.22)$ and $\mathrm{OA}(\mathrm{p}=.12)$ or between YA and OD $(\mathrm{p}=.27)$.

Pairwise comparison by hemisphere revealed that YA had higher mean amplitude in the left compared $(\mathrm{M} \pm \mathrm{SE}=3.51 \pm 0.29) \quad$ to right hemisphere $(\mathrm{M} \pm \mathrm{SE}=2.45 \pm 0.22 ; \mathrm{p}=.00009)$, whereas $\mathrm{OD}$ had higher mean amplitude in the right $(\mathrm{M} \pm \mathrm{SE}=2.98 \pm 0.22)$ compared to left hemisphere $(\mathrm{M} \pm \mathrm{SE}=2.48 \pm 0.28 ; \mathrm{p}=.044)$ There was no difference between left $(\mathrm{M} \pm \mathrm{SE}=2.08 \pm 0.29)$ and right $(\mathrm{M} \pm \mathrm{SE}=1.79 \pm 0.22)$ hemispheres in the OA group $(\mathrm{p}=.26)$

There was also a main effect of stimulus $\left(\mathrm{F}_{1.6,87.49}=5.10, \mathrm{p}=.012\right.$, partial $\left.\eta^{2}=0.09\right)$. There was higher mean amplitude for new word $(\mathrm{M} \pm \mathrm{SE}=2.74 \pm 0.19)$ compared to L-word $(\mathrm{M} \pm \mathrm{SE}=2.21 \pm 0.15 ; \mathrm{p}=.029)$ and higher mean amplitude for $\mathrm{X}$-word $(\mathrm{M} \pm \mathrm{SE}=2.70 \pm 0.16)$ compared to L-word $(\mathrm{p}=.003)$. There was no difference between new word and $\mathrm{X}$-word $(\mathrm{p}=1.00)$. 
There was also a main effect of group $\left(\mathrm{F}_{2,53}=6.35, \mathrm{p}=.003\right.$, partial $\left.\eta^{2}=0.19\right)$. YA $(\mathrm{M} \pm \mathrm{SE}=3.05 \pm 0.22)$ had higher $\mathrm{MA}$ than $\mathrm{OA}(\mathrm{M} \pm \mathrm{SE}=1.94 \pm 0.23 ; \mathrm{p}=.003)$, and $\mathrm{OD}(\mathrm{M} \pm \mathrm{SE}=2.73 \pm 0.22)$ had higher MA than $\mathrm{OA}(\mathrm{p}=.048)$. There was no difference between YA and OD $(p=.73)$.

\subsection{Topographical distributions; Encoding and recognition blocks}

Topographical distribution was visually inspected only; therefore, interpretation is limited. During the encoding phase, a distinct scalp topography pattern was evident for each group across all conditions. YA typically displayed a bilateral posterior topography for the late posterior positivity, while OA were more centrally mediated and OD were more rightwardbiased. During the recognition phase at parietal sites, there was a similar pattern across groups, whereby YA exhibited a largely left-sided or bilateral late positivity, while OA displayed a more central or slightly left-lateralised distribution, and OD were distinctly right-lateralised. The spread of activation from YA to OA to OD appears to shift from a focused left/bilateral activity to less focused, unilateral right hemisphere activity, especially during encoding (see Figure $\mathbf{5}$ ). During the recognition phase at frontal sites, a frontocentral scalp activation was present, typical of the P200 event-related potential, which appeared to be more anteriorly centred in the YA compared to OA and OD, particularly in new word and L-word conditions (see Figure $\underline{6}$ ). 


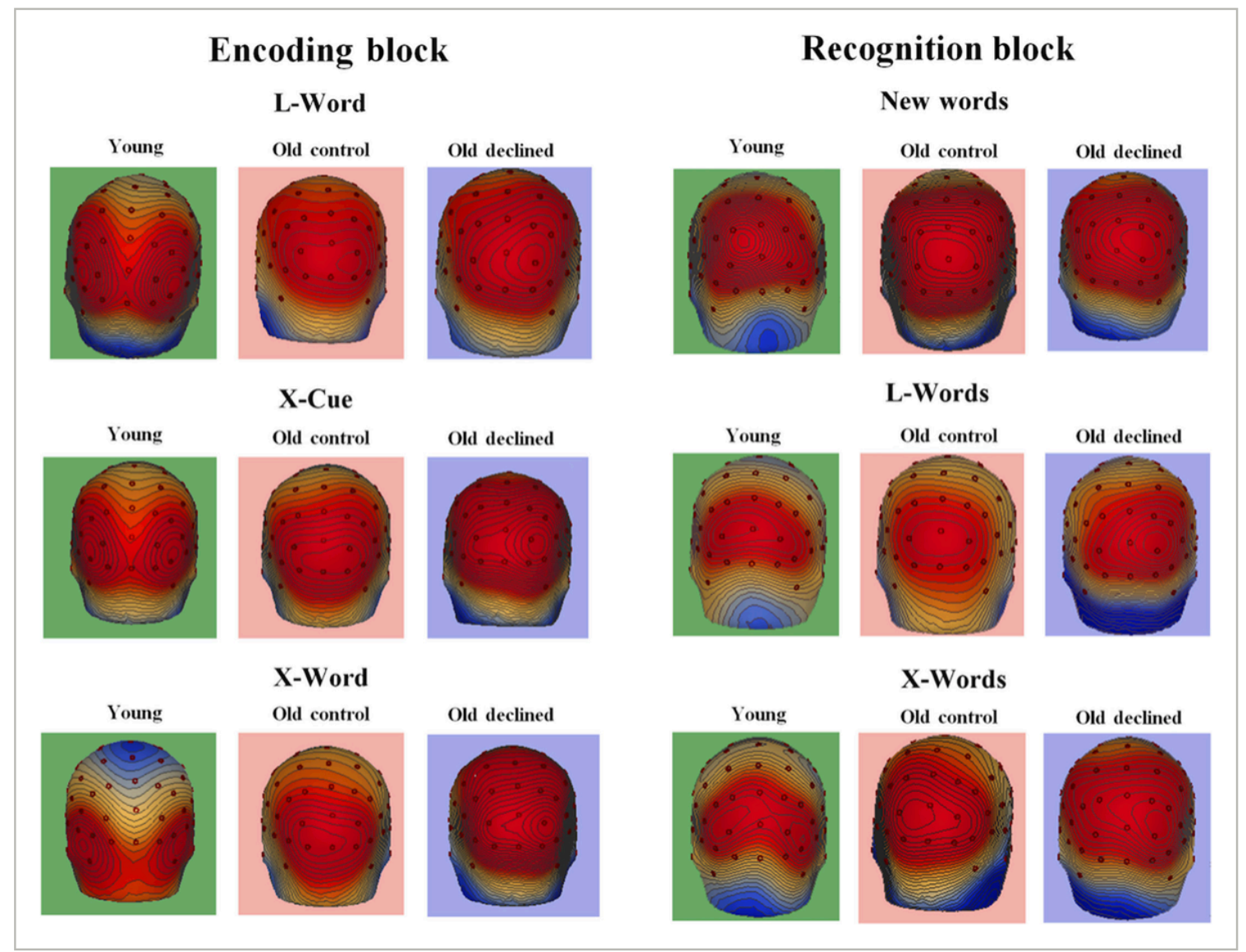

\section{Figure 5}

Scalp topographical distributions for the anterior ERP waveform component for different stimulus conditions for young (YA), older control (OA) and older adults with relative memory impairment (OD) in encoding (left) and recognition (right) blocks 


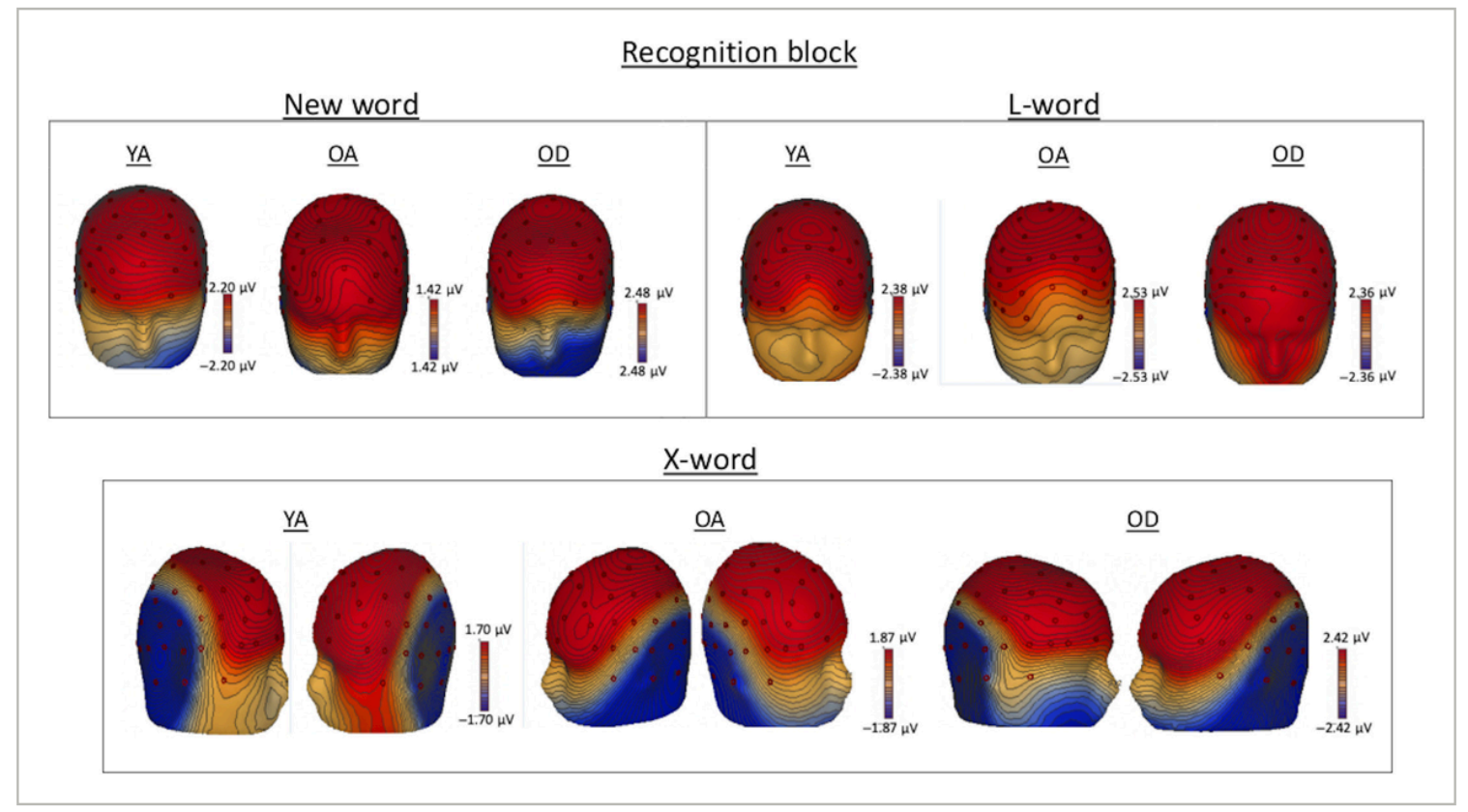

\section{Figure 6}

Scalp topographical distributions for the anterior ERP waveform component for different stimulus conditions for young (YA), older control (OA) and older adults with relatively memory impairment (OD) in recognition block

\section{$\underline{\text { 3.7 Lateralisation of waveform components and relationship to behavioural measures }}$}

There were no significant associations between lateralisation index of the parietal LPP or frontal (P2) waveform during recognition and behavioural measures (accuracy and reaction time; $t_{\text {range }(\text { uncorrected) }}=-0.45$ to $\left.0.54, p_{\text {range }}=.017-.96\right)$. See Appendix $\underline{\mathbf{S 1}}$ : Section $\underline{\mathbf{2} \mathbf{1}}$ for further information. 
SELF-INITIATED LEARNING, AGING, AND EVENT-RELATED POTENTIALS

\section{Discussion}

The current study examined behavioural and electrophysiological effects of cues to selfinitiate learning on the encoding and subsequent recognition of visually presented words in a sample of younger adults (YA), older control adults (OA) and older adults with relative memory impairment (OD). Based on previous research which suggests that older adults engage in less spontaneous, elaborative encoding and that both OA and OD groups benefit less from cues to learn (Hogan et al., 2006), we hypothesised that OA and OD would display poorer memory performance than YA. In terms of electrophysiological activity, during encoding we hypothesised that differences in effortful self-initiated encoding of words as a function of age would be indexed by age-related amplitude differences in later electrophysiological components (late posterior positivity, LPP). During recognition, we investigated age differences in the frontally mediated P200 and the LPP, components involved in recollective processing during retrieval. We predicted that, while YA would show a left lateralisation over posterior regions, the OA and OD groups would have a more generalised, bilateral scalp distribution instead, consistent with the scaffolding theory of ageing and cognition (STAC; Park \& Reuter-Lorenz, 2009; Reuter-Lorenz \& Park, 2014).

Behaviourally, our results provide a partial replication of the effects observed in the previous study which used this paradigm with YA, OA and OD groups (Hogan et al., 2006), again showing superior memory performance in the young compared to both older groups (but no differences between OA and OD groups). However, unlike Hogan and colleagues, we did not find evidence of selectively enhanced memory for L-words relative to $\mathrm{X}$-words in younger adults compared with older control adults and older relatively impaired adults. Instead, we found that YA performed better than both OA and OD across 
SELF-INITIATED LEARNING, AGING, AND EVENT-RELATED POTENTIALS

all recognition conditions with no difference between OA and OD. Differences between the current study and the findings of Hogan et al. (2006) may reflect differences in the encoding and recognition demands across the two studies. Notably, to facilitate reliable ERP comparisons between L-word and X-word stimuli during encoding and recognition, the current study used a larger number of words than Hogan et al. (2006): specifically, 120 words as opposed to 80 words. This may have changed the demand characteristics of the task and resulted in poorer discrimination between L-words and X-words during recognition. That notwithstanding, the differential L-word and X-word electrophysiological activities observed during encoding suggest differences in the way the two stimulus sets were processed. Reaction time (RT) data also reflected the YA group's superior performance at recognition for L-words compared to the two older adult groups; however, there was no group difference for X-words, suggesting that there was greater fluency of access to L-words in the young compared to older adult groups. Again, the OA and OD groups did not differ in response speed; whatever approach to processing the OD group adopted, it appears to have normalised their performance relative to their agematched control group. The YA and OD groups also had faster reaction time for L-word compared to X-word, indicating that the previously cue to learn (L-cue) and inhibited (Xcue) during encoding had influenced the later accessibility of words at recognition for these groups.

With respect to electrophysiological findings, during cue presentation, early visual P100 attentional deployment presented with contrasting parietal distribution across the groups particularly for X-cues. More specifically, the YA group appeared to have a left-lateralised distribution, OA displayed a more central distribution, while ODs were distinctly right- 


\section{SELF-INITIATED LEARNING, AGING, AND EVENT-RELATED POTENTIALS}

lateralised in their activation pattern. This distinction between young and older adults of early attentional activation during cue presentation may be indicative of changes to neural systems in older adults, perhaps affecting later poorer performance during the recognition stage. Interestingly, tentative evidence from visualisation of topographical distribution revealed that while younger adults displayed a bilateral posterior scalp distribution for the LPP, the same component of older control adults was more centrally located, while older relatively memory-impaired adults were more rightward-biased (see Figure 5). These findings highlight possible strategic differences between the three groups during encoding. However, as the topographical maps were visually inspected only, the interpretation is limited. The P100 activation also discriminated between L- and X-word presentation, with greater mean amplitude for L-word across groups, indicating that the cue successfully helped to deploy visual attentional resources early to word learning across all groups, even though we observed higher MA for cues to inhibit, X-cue, relative to cues to learn, L-cue, at this waveform component. Consistent with previous research (Davis, Dennis, Daselaar, Fleck, \& Cabeza, 2008), we observed a reduction in ERP component amplitudes over parietal scalp during encoding component in older adults relative to YA, although there was no statistically significant difference between YA and OD. Specifically, older controls showed significantly reduced mean amplitude late posterior positivity (LPP) compared to younger adults at parietal sites during encoding. This may suggest diminished strategic encoding operations in the older adults compared to young.

During recognition, the young showed an early frontal P200 modulation with higher mean amplitude compared to the OA; however, OD displayed higher activity across frontal sites compared to OA. Moreover, only in the young did this component differentiate L-words 


\section{SELF-INITIATED LEARNING, AGING, AND EVENT-RELATED POTENTIALS}

from X-words suggesting greater early frontal engagement in the young based on prior learning and may suggest an early failure to select and maintain a retrieval mode during recognition in the old, perhaps due to reduction of frontal lobe capacity. A later parietal positivity during recognition discriminated word types which may demonstrate successful task engagement. Across groups, greater electrophysiological activity was evident for new word and X-word compared to L-word. One interpretation of this finding is that the greater early visual attention allocated to L-words during encoding may result in a reduction of LPP activity necessary to discern L-words during recognition, whereas greater resources may be required to discern the previously inhibited X-words and unseen new words.

Further differences between groups were observed during recognition, and we observed a reduction in LPP component amplitudes in older adults relative to YA, similar to encoding; however, ODs had higher parietal electrophysiological activity than OA. Across word types, similar to the pattern of early electrophysiological activation observed during encoding, YA showed more left hemisphere dominance - as predicted by the commonly reported left parietal old/new effect (Rugg \& Curran, 2007; Wolk et al., 2009)—with larger mean amplitudes than OA and OD across recognition stimuli over left parietal scalp. Older controls displayed a more central distribution, while older adults with relative memory impairment displayed greater right-lateralised in their activation. While these results suggest that younger adults responded selectively to stimuli with larger amplitude left parietal componentry, the overall pattern of results during recognition highlights a global shift in activation patterns, with the OD group showing a more rightward bias, OA being more centrally distributed and YA more leftward-biased. This reduction in lateralisation/hemispheric asymmetry may reflect compensatory scaffolding as reported by 


\section{SELF-INITIATED LEARNING, AGING, AND EVENT-RELATED POTENTIALS}

the scaffolding theory of ageing and cognition (STAC; Park \& Reuter-Lorenz, 2009; Reuter-Lorenz \& Park, 2014). This pattern of ERP waveform componentry may be electrophysiological evidence of dedifferentiation, where the ageing brain accommodates anatomical and physiological changes by re-organising activation patterns between neural assemblies (Cabeza et al., 2002; Sleimen-Malkoun, Temprado, \& Hong, 2014; Ward, 2006), as left hemisphere specialisation is lost and accommodated by bilateral/right hemisphere activation in the older adults. However, as lateralisation indices of the waveform components were not significantly associated with behavioural measures, we cannot definitively state that these changes to activation patterns in the older groups are indicative of compensatory approaches.

The finding that YA and OD displayed better behavioural reaction time for L-words in comparison with $\mathrm{X}$-words could be attributed to the phenomenon known as directed forgetting. Participants were instructed not to learn any word preceded by an X-cue, which could also be interpreted as an instruction to forget these words. The learn/no-learn paradigm is similar to the item-cueing method of directed forgetting, in which a 'forget' cue or a 'remember' cue is presented immediately before, during or after presentation of a target stimulus such as a word (Muther, 1965). Subjects are then tested on their ability to recall target stimuli, with expected results reflecting increased recognition of items accompanied by the 'remember' cue, thus inferring stronger encoding of this stimulus compared to those accompanied by a 'forget' cue (Depue, 2012). Two common interpretations as to how this directed forgetting effect is achieved through encoding are selective rehearsal and inhibitory control. Selective rehearsal attempts to explain it through a passive and non-inhibitory account, where rehearsal and elaborate encoding processes 
SELF-INITIATED LEARNING, AGING, AND EVENT-RELATED POTENTIALS

acting on the to-be-remembered item are emphasised, while to-be-forgotten items are subject to passive forgetting (Bjork, 1989). The inhibitory control theory postulates that episodic encoding of items to be forgotten is actively inhibited (rather than memories of those items passively decaying away), suggesting that intentional forgetting is effortful. Interestingly, during encoding there was greater parietal electrophysiological activity for X-cue relative to L-cue in the early visual P100 component, perhaps indication of greater exertion of effort for inhibition or intentional forgetting. However, L-word activity was higher than $\mathrm{X}$-word at this waveform component, which may suggest that greater effort is employed in the preparation to inhibit during cue presentation. FMRI evidence reveals prefrontal and parietal activations in response to attempts to forget a recent item (Anderson \& Hanslmayr, 2014). The ability to intentionally forget via inhibitory processes has been found to be affected by age, with older adults showing a lower level of neural recruitment of regions known to support attempts at forgetting by recruitment of inhibition mechanisms, such as right frontal and parietal regions, when compared to young adults (Rizio \& Dennis, 2014).

Age-related memory decline associated with frontal mechanisms may underlie retrieval processes in the current study. While deficits at frontal regions may play a role in the poorer performance of older adults in this study, a number of studies have shown that this region can be selectively enhanced, under specific experimental conditions, to improve memory performance. For example, Logan et al. (2002) found that, although under-recruitment of left prefrontal areas by older subjects occurred during intentional learning of verbal material, this age-related under-recruitment was eliminated when both age groups were instructed to perform a semantic judgement task on each word during the encoding phase. 


\section{SELF-INITIATED LEARNING, AGING, AND EVENT-RELATED POTENTIALS}

These results suggest that by inducing older adults to engage in effective encoding strategies, it may be possible to activate left frontal regions and facilitate subsequent memory. One major difference between the current study and the study by Logan and colleagues is that we sought to examine group differences in self-initiated encoding; therefore, no explicit encoding instructions were given other than to learn the L-words. The L-cue acted as a stimulus designed to remind participants to self-initiate learning strategies to learn the proceeding L-words; however, these strategies needed to be self-initiated. Thus, although the capacity to engage in effective encoding processes that minimise age-related differences in subsequent memory is apparently preserved, research suggests that older adults may often fail to self-initiate these processes, and thus, explicit instructions may be needed to facilitate or activate these learning mechanisms. The finding that age-related differences in memory can be ameliorated by asking participants to perform a semantic task was also reported by Craik and Byrd (1982) and by Troyer, Häfliger, Cadieux, and Craik (2006).

While this research focused on early and late posterior and anterior electrophysiological components during an old/new paradigm, the dual process models assume that there are two distinct processes in recognition memory: familiarity and recollection (Stróżak, Bird, Corby, Frishkoff, \& Curran, 2016). Future studies may extend the research to investigate familiarity and recollection components of recognition memory. Females consisted of 78\% of the participants; however, the study may not have been suitably powered to detect significant sex differences in the groups. A balance of females and males in each group is recommended for future research. It is also recommended that future research include quantitative analysis of topographies, the lack of which is a limitation of the current study. 
Here, we have reported the behavioural and electrophysiological correlates of the explicit instruction to learn a particular subset of stimuli in a word learning task with young (YA), older control adults (OA) and older adults with relative memory impairment (OD). Results show that, while behavioural performance was best in the YA group, who displayed the traditional pattern of left-lateralised ERP componentry, ERP patterns also revealed-in particular, the late posterior positivity — a STAC-style reduction in hemispheric asymmetry during encoding and recognition, especially for the OD group. Both older groups performed comparably on behavioural performance, possibly suggesting that some manner of cortically driven compensation was at work during the recognition phase, specifically increased parietal and frontal activity in the OD group. These data may indicate that providing explicit cues to learn words promotes the recruitment of adapted neural resources/regions in older adults. While further work will be needed to determine the cortical generators responsible for these scalp-recorded patterns, our data support the idea that the ageing brain retains the ability to recruit and repurpose specific regions of cortex in order to compensate for the limitations of the changes in neural systems. 


\section{Acknowledgements}

This work was funded via a research collaboration between NUI Galway and GlaxoSmithKline (GSK) UK. Sincere thanks to Robert Lai and Neil Upton (Neurosciences CEDD, GlaxoSmithKline, Harlow, UK), and to Andrew Allen, Sean Commins, Caoilainn Doyle, Michelle Loftus (Maynooth University) and Greta Warren (Trinity College Dublin) for feedback on a draft of this paper.

\section{Data Accessibility statement}

The database containing the primary data used in this study titled Kenneyetal_2018_database.sav will be made available on Figshare by Wiley.

\section{Conflict of Interest}

The authors declare no conflict of interest.

\section{Author Contribution}

JPMK pre-processed the EEG data, conducted statistical analysis and co-wrote the manuscript. MAK designed the paradigm, set up the EEG experiment, collected the data and contributed to the manuscript. MJH designed the paradigm and co-wrote the manuscript. RAPR contributed to the EEG analysis, created images and co-wrote the paper. PD contributed to the manuscript preparation and provided statistical advice. $\mathrm{NH}$ contributed to secondary data analysis. DG, CW and CC contributed to the literature review and manuscript preparation. 


\section{References}

Addante, R.J., de Chastelaine, M. \& Rugg, M.D. (2015) Pre-stimulus neural activity predicts successful encoding of inter-item associations. Neuroimage, 105, 21-31.

Addante, R.J., Watrous, A.J., Yonelinas, A.P., Ekstrom, A.D. \& Ranganath, C. (2011) Prestimulus theta activity predicts correct source memory retrieval. PNAS, 108, 1070210707.

Alexander, M.P., Stuss, D. \& Gillingham, S. (2009) Impaired list learning is not a general property of frontal lesions. J. Cognitive. Neurosci., 21, 1422-1434.

American Electroencephalographic Society (1994). Guidelines for standard electrode position nomenclature. Journal of Clinical Neurophysiololgy, 11, 111-113.

Anderson, M.C. \& Hanslmayr, S. (2014) Neural mechanisms of motivated forgetting. Trends Cogn. Sci, 18, 279-292.

Baltes, P.B. (1997) On the Incomplete Architecture of Human Ontogeny. Am. Psychol., 52, 366-380.

Bishop, N.A., Lu, T. \& Yankner, B.A. (2010) Neural mechanisms of ageing and cognitive decline. Nature, 464, 529-535.

Bjork, R.A. (1989) Retrieval inhibition as an adaptive mechanism in human memory. In Varieties of memory and consciousness: Essays in honour of Endel Tulving. Hillsdale, NJ, US: Lawrence Erlbaum Associates, Inc., pp. 309-330.

Bourisly, A.K. \& Shuaib, A. (2018) Neurophysiologial effects of aging: A P200 ERP study. Transl Neurosci, 9, 61-66.

Bressler, S. L. \& Menon, V. (2010) Large-scale brain networks in cognition: emerging methods and principles. Trends Cogn. Sci., 14, 277-290

Buckner, R.L. (2004) Memory and Executive Function Review in Aging and AD: Multiple Factors that Cause Decline and Reserve Factors that Compensate. Neuron, 44,195-208.

Cabeza, R., Anderson, N. D., Locantore, J. K., \& Mcintosh, A. R. (2002). Aging gracefully: Compensatory brain activity in higher performing adults. NeuroImage, 17, 1394- 1402. 
Craik, F. I. M. (1986). A functional account of age differences in memory. In F. Klix, \& H. Hagendorf (Eds.), Human memory and cognitive capabilities, mechanisms and performances (pp. 409-422). Amsterdam: Elsevier

Craik, F. I. M., Routh, D. A., \& Broadbent, D. E. (1983). On the transfer of information from temporary to permanent memory [and Discussion]. Philosophical Transactions of the Royal Society B: Biological Sciences, 302, 341-359.

Craik, F.I.M. \& Byrd, M. (1982) Aging and cognitive deficits: The role of attentional resources. In Craik FIM \& Trehub SE (eds), Aging and cognitive processes, Plenum Press, New York, pp 191-211.

Craik, F.I.M. \& Rose, N.S. (2012) Memory encoding and aging: a neurocognitive perspective. Neurosci. Biobehav. R., 36, 1729-1739.

Curran, T., \& Dien, J. (2003). Differentiating amodal familiarity from modality-specific memory processes: An ERP study. Psychophysiology, 40, 979- 988

Davis, S.W., Dennis, N.A., Daselaar, S.M., Fleck, M.S. \& Cabeza, R. (2008) Que PASA? The posterior-anterior shift in aging. Cerebral cortex (New York, NY : 1991) 18, 12011209.

de Chastelaine, M., \& Rugg, M. D. (2015). The effects of study task on prestimulus subsequent memory effects in the hippocampus. Hippocampus, 25, 1217-1223.

DeKeyser, R. (2008) 11 Implicit and Explicit Learning. The handbook of second language acquisition, 27, 313.

Dennis, N.A. \& Cabeza, R. (2008) Neuroimaging of healthy cognitive ageing. In Craik FIM \& Salthouse TA (ends) The Handbook of Ageing and Cognition, 3rd ed. Psychology Press, New York, pp 1-54.

Depue, B. E. (2012) A neuroanatomical model of prefrontal inhibitory modulation of memory retrieval. Neurosci. Biobehav. Rev., 36, 1382-1399.

Dimitrova, J., Hogan, M., Khader, P., O’Hora, D., Kilmartin, L., Walsh, J. C., \& AndersonHanley, C. (2016) Comparing the effects of an acute bout of physical exercise with an acute bout of interactive mental and physical exercise on electrophysiology and executive functioning in younger and older adults. Aging Clin. Exp. Res., 1-9.

Dockree, P. M., Brennan, S., O’Sullivan, M., Robertson, I. H., \& O’Connell, R. G. (2015) Characterising neural signatures of successful aging: Electrophysiological correlates of preserved episodic memory in older age. Brain Cognition, 97, 40-50. 
Einstein, G. O., McDaniel, M. A., Richardson, S. L., Guynn, M. J., \& Cunfer, A. R. (1995) Aging and prospective memory: examining the influences of self-initiated retrieval processes. J. Exp. Psychol. Learn., 21, 996.

Erika-Florence, M., Leech, R. \& Hampshire, A. (2014) A functional network perspective on response inhibition and attentional control. Nat. Commun. 5, 1-12.

Folstein, M.F., Folstein, S.E. \& McHugh, P.R. (1975) A practical method for grading the cognitive state of patients for clinician. J. Psychiat. Res., 12, 189-198.

Ford, J. M., Sullivan, E. V., Marsh, L., White, P. M., Lim, K. O., \& Pfefferbaum, A. (1994). The relationship between P300 amplitude and regional gray matter volumes depends upon the attentional system engaged. Electroencephalography and Clinical Neurophysiology, 90, 214- 228.

Friedman, N. P. \& Miyake, A. (2017) Unity and diversity of executive functions: Individual differences as a window on cognitive structure. Cortex, 86, 186-204 (2017).

Gonsalves, B. D., Kahn, I., Curran, T., Norman, K. A., \& Wagner, A.D. (2005). Memory strength and repetition suppression: Multimodal imaging of medial temporal cortical contributions to recognition. Neuron, 47, 751- 761.

Grady, C.L., Sarraf, S., Saverino, C. \& Campbell, K. (2016). Age differences in the functional interactions among the default, frontoparietal control and dorsal attention networks. Neurobiol. Aging, 41, 159-172.

Gunning-Dixon, F.M., Brickman, A.M., Cheng, J.C. \& Alexopoulos, G.S. (2009) Aging of cerebral white matter: a review of MRI findings. Int. J. Geriatr. Psych., 24, 109-117

Gutchess, A.H., Ieuji, Y., Federmeier, K.D. (2007) Event-related Potentials Reveal Age Differences in the Encoding and Recognition of Scenes. J. Cogn. Neursoci., 19, 1089-1103

Hampshire, A. \& Sharp, D.J. (2015) Contrasting network and modular perspectives on inhibitory control. Trends Cogn. Sci., 19, 445-452.

Hertzog, C., Mcguire. C.L., Horhota. M., \& Jopp, D. (2010) Does believing in "use it or lose it" relate to self-rated memory control, strategy use and recall? Int. J. Aging Hum. Dev., 70, 1-23.

Hogan, M.J., Carolan, L., Roche RAP, Dockree, P.M., Kaiser, J., Bunting, B.P. \& Lawlor, B.A. (2006) Electrophysiological and information processing variability predicts memory decrements associated with normal age-related cognitive decline and Alzheimer's disease (AD). Brain Res., 1119, 215-226. 
Hogan, M., Kilmartin, L., Keane, M. \& Collins, P. (2012) Electrophysiological entropy in younger adults, older controls and older cognitively declined adults. Brain Res., 1445, 110 .

Hogan, M.J., Swanwick, G.R.J., Kaiser, J. \& Rowan, M. (2003) Memory-related EEG power and coherence reductions in mild Alzheimer's disease. Int. J. Psychophysiol., 49, $147-163$.

Iordan A.D., Cooke K.A., Moored K.D., Katz B., Buschkuehl, M., Jaeggi, S.M., Jonides,J., Peltier S.J., Polk T.A., Reuter-Lorenz P.A. (2018) Aging and Network Properties: Stability Over Time and Links with Learning during Working Memory Training. Front. Aging Neursci. 9, 1-18.

Jastak, J. \& Jastak, S. (1978) Wide range achievement test, Revised edition. Jastak Associate, Wilmington.

Kenney, J. P. M., McPhilemy, G., Scanlon, C., Najt, P., McInerney, S., Arndt, S., Byrne, F., Leemans, A., Jeurissen, B., Hallahan, B., McDonald, C. \& Cannon, D. M.(2017). The arcuate fasciculus and verbal deficits in psychosis. Translational

neuroscience, 8, 117-126.

Kirchhoff, B. A., Anderson, B. A., Barch, D. M., \& Jacoby, L. L. (2012) Cognitive and neural effects of semantic encoding strategy training in older adults. Cereb. Cortex, 22, 788-799.

Kirchhoff, B.A. \& Buckner, R.L. (2006) Functional-anatomic correlates of individual differences in memory. Neuron, 51, 263-274.

Lawson, A.L., Guo, C. \& Jiang, Y. (2007) Age effects on brain activity during repetition priming of targets and distractors. Neuropsychologia, 45, 1223-1231.

Li, R., Nguyen, T., Potter, T. \& Zhang, Y. (2019). Dynamic cortical connectivity alteration associated with Alzheimer's disease. An EEG and fNIRS integration study. Neuroimage, 21, 1-11.

Linden, D.E. (2005) The p300: where in the brain is it produced and what does it tell us?. Neuroscientist, 11, 563. 
Logan, J.M., Sanders, A.L., Snyder, A.Z., Morris, J.C. \& Buckner, R.L. (2002) Underrecruitment and nonselective recruitment: dissociable neural mechanisms associated with aging. Neuron, 33, 827-840

Matsui, M., Suzuki, M., Zhou, S.Y., Takahashi, T., Kawasaki, Y., Yuuki, H., Kato, K., Kurachi, M. (2008) The relationship between prefrontal brain volume and characteristics of memory strategy in schizophrenia spectrum disorders. Prog.Neuropsychopharmacol. Biol. Psychiatry, 32,1854-1862.

Muther, W. S. (1965) Erasure or partitioning in short-term memory. Psychon. Sci., 3, 429430.

Naik, S., Banerjee, A., Bapi, R.S., Deco, G. \& Roy, D. (2017) Metastability in senescence. Trends Cogn. Sci., 21, 509-521.

Naveh-Benjamin, M., Brav, T.K. \& Levy, O. (2007) The associative memory deficit of older adults: the role of strategy utilization. Psychol. Aging, 22, 202-208.

Nelson, H.E. (1982) National adult reading test (NART: test manual. NFER-Nelson, Windsor.

O'Connell, R. G., Balster, J. H., Kilcullen, S. M., Campbell, W., Bokde, A. W., Lai, R., Upton, N. \& Robertson, I. H.(2012). A simultaneous ERP/fMRI investigation of the P300 aging effect. Neurobiology of Aging, 33, 2448- 2461.

O’Hora, D., Schinkel, S., Hogan, M. J., Kilmartin, L., Keane, M., Lai, R. \& Upton, N. (2013) Age-related task sensitivity of frontal EEG entropy during encoding predicts retrieval. Brain Topogr., 26, 547-557.

Osorio, A., Fay, S., Pouthas, V. and Ballesteros, S. (2010) Ageing affects brain activity in highly educated older adults: An ERP study using a word-stem priming task. Cortex, 46, $522-534$.

Paller, K. A., \& Wagner, A. D. (2002). Observing the transformation of experience into memory. Trends in Cognitive Neuroscience, 6, 93-102.

Park, D.C. \& Reuter-Lorenz, P. (2009) The adaptive brain: Aging and neurocognitive scaffolding. Annu. Rev. Psychol. 60, 173-196.

Perfect, T.J. \& Dasgupta, Z.R.R. (1997) What underlies the deficit in reported recollective experience in old age? Mem, Cognit, 25, 849-858. 
Polich, J. (2007). Updating P300: An integrative theory of P3a and P3b. Clinical Neurophysiology, 118, 2128-2148.

Puccioni, O., \& Vallesi, A. (2012). Conflict resolution and adaptation in normal aging: The role of verbal intelligence and cognitive reserve. Psychological Aging, 27, 1018-1026.

Reuter-Lorenz, P.A., Jonides, J., Smith. E.E., Hartley, A., Miller, A., Marsheutz, C. \& Koeppe, R.A. (2000) Age differences in the frontal lateralization of verbal and spatial working memory revealed by PET. J. Cognitive Neurosci., 12, 174-87.

Reuter-Lorenz, P.A. \& Park, D.C. (2014) How does it STAC up? Revisiting the scaffolding theory of aging and cognition. Neuropsychol. Rev., 24, 355-370.

Richman, J. and Moorman, J. (2000) Physiological time-series analysis using approximate entropy and sample entropy. Am. J. Physiol. Heart Circ. Physiol., 278, 2039-2049

Ritchie, K. \& Lovestone, S. (2002) The dementias. The Lancet, 360, 1759-1766.

Rizio, A. A., \& Dennis, N. A. (2014) The cognitive control of memory: age differences in the neural correlates of successful remembering and intentional forgetting. PloS one, 9, e87010.

Rugg, M.D. \& Curran, T. (2007) Event-related potentials and recognition memory. Trends Cogn Sci., 11, 251-257.

Salthouse, T.A. (2011) Effects of age on time-dependent cognitive change. Psychol. Sci. ,22, 682-688.

Schaefer, A., Pottage, C. L., \& Rickart, A. J. (2011). Electrophysiological correlates of remembering emotional pictures. NeuroImage, 54, 714- 724.

Sleimen-Malkoun, R., Temprado, J. J., \& Hong, S. K. (2014). Aging induced loss of complexity and dedifferentiation: Consequences for coordination dynamics within and between brain, muscular and behavioural levels. Frontiers in Aging Neuroscience, 6, 140.

Spreng, R.N., Stevens, W.D., Chamberlain, J.P., Gilmore, A.W. \& Schacter, D.L., (2010) Default network activity, coupled with the frontoparietal control network, supports goal-directed cognition, NeuroImage , 53, 303-317 
Stoub, T. R., Detoledo-Morrell, L., \& Dickerson, B. C. (2014) Parahippocampal white matter volume predicts Alzheimer's disease risk in cognitively normal old adults. Neurobiol. Aging., 35, 1855-1861.

Stróżak, P., Bird, C.W., Corby, K., Frishkoff, G. \& Curran, T. (2016) FN400 and LPC memory effects for concrete and abstract words. Psychophysiology, 53, 1669-1678.

Strunk, J. \& Duarte, A., (2019) Prestimulus \& poststimulus oscillatory activity predicts successful episodic encoding for both young and older adults. Neurobiol. Aging. 77, 1-12.

Swanwick, G.R.J., Coen, R.F., Lawlor, B.A, O'Mahony, D., Walsh, J.B. \& Coakley, D. (1996) Utility of Ischemic Scores in the Differential Diagnosis of Alzheimer's Disease and Ischemic Vascular Dementia. Int. Psychogeriatr., 8, 413-424.

Troyer, A.K., Häfliger, A., Cadieux, M.J. \& Craik, F.I.M. (2006) Name and face learning in older adults: effects of level of processing, self-generation, and intention to learn. $J$. Gerontol. B. Psychol.. Sci Soc. Sci., 61, 67-74.

Tsivilis, D., Allan, K., Roberts, J., Williams, N., Downes, J. J., \& El-Deredy, W. (2015). Old-new ERP effects and remote memories: The late parietal effect is absent as recollection fails whereas the early mid-frontal effect persists as familiarity is retained. Frontiers in Human Neuroscience, 9, 532.

Tsivilis, D., Otten, L. J., \& Rugg, M. D. (2001). Context effects on the neural correlates of recognition memory: An electrophysiological study. Neuron, 31, 497- 505.

Unsworth, N. (2009). Individual differences in self-initiated processing at encoding and retrieval: A latent variable analysis. $Q J$ Exp Psychol, 62, 257-266.

Vallesi, A., McIntosh, A. R., \& Stuss, D. T. (2009) Temporal preparation in aging: A functional MRI study. Neuropsychologia, 47, 2876-2881.

Voss, J. L., Schendan, H. E., \& Paller, K. A. (2010). Finding meaning in novel geometric shapes influences electrophysiological correlates of repetition and dissociates perceptual and conceptual priming. NeuroImage, 49, 2879-2899.

Wagner, A.D., Koutstaal, W. \& Schacter, D.L. (1999) When encoding yields remembering: Insights from event-related neuroimaging. Philos. Trans. R. Soc. Lond. Ser. B., 354, $1307-1324$

Ward, N. S. (2006). Compensatory mechanisms in the aging motor system. Ageing Research Reviews, 5, 239- 254. 
Weschler, D. (1987) The Wechsler memory scale-revised manual. The psychological corporation, 555 Academic Court, San Antonio, TX 78204-2498.

Wierzba, M., Riegal, M, Wypych, M, Jednoróg, K., Grabowska, A. \& Marchewka, A. (2018) Cognitive control over memory - individual differences in memory performance for emotional and neutral material. Sci Rep, 8, 3808.

Wolk, D.A., Sen, N.M., Chong H., Riis, J.L., McGinnis, S.M., Holcomb, P.J., \& Daffner, K.R. (2009) ERP correlates of item recognition memory: effects of age and performance. Brain Res., 1250, 218-231.

Zigmond, A.S. \& Snaitth, R.P. (1983) The hospital anxiety and depression scale. Act Psychiat. Scand., 67, 361-370. 


\section{Appendix}

\section{Recognition Hit Rate}

A 3 (group: Young, Older-Control, Older adults with relative cognitive impairment) x 2 (gender: female, male) x 3 (Stimulus: L word, X-word, new-word) mixed factorial ANOVA revealed a significant main effect of Group, $F_{2,54}=5.22 ; P=0.008$, partial $\mathrm{h}^{2}=$ 0.16 with better overall hit rate in Younger adults $(\mathrm{M} \pm \mathrm{SE}=73.49 \pm 2.25)$ when compared with Older-Controls $(\mathrm{M} \pm \mathrm{SE}=62.08 \pm 3.21)(P=0.025)$. Hit rate of the Younger adults compared to Older relatively impaired adults was not statistically significant $(\mathrm{M} \pm \mathrm{SE}=$ 62.73 \pm 3.77$)(P=0.05)$. The difference between Older-Controls and Older relatively impaired was not statistically significant. There was also a main effect of Stimulus, (sphericity was violated, therefore Greenhouse-Geisser corrected values were used), $F_{1.29,69.67}=10.36 ; P=0.001$, partial $\mathrm{h}^{2}=0.16$ with better accuracy for New words $(\mathrm{M} \pm \mathrm{SE}$ $=75.75 \pm 2.52)$ compared with $\mathrm{X}$-words $(\mathrm{M} \pm \mathrm{SE}=55.75 \pm 3.42)(P=1.34 \mathrm{E}-9)$. The Group $\mathrm{x}$ Stimulus nor the Group x Stimulus x Gender interaction effects were not significant, $F_{2.6}$, $69.67=1.87 ; P=0.15, F_{2.6,69.67}=1.37 ; P=0.26$ (see Supplementary Figure 1a). 


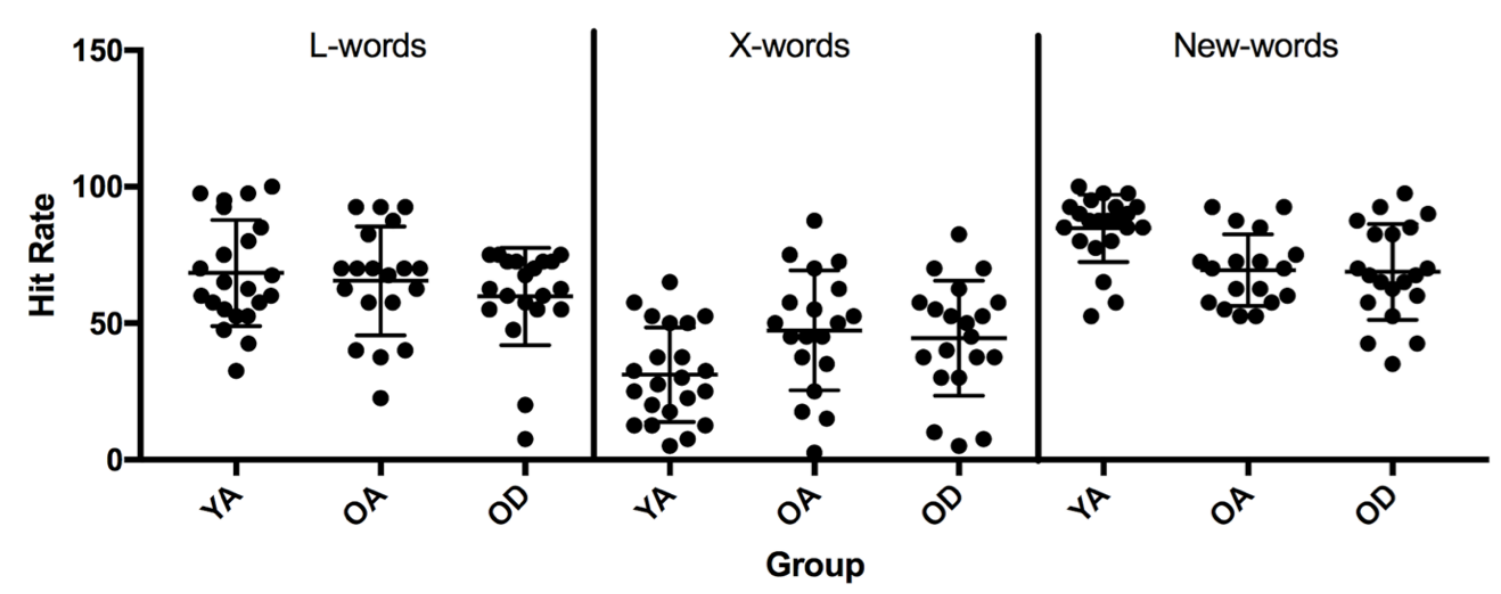

Figure 1A: Scatter plots (with mean and IQR) showing recognition memory accuracy (Hit Rate) for L-words, X-words and New words for Young (YA), Older control (OA) and Older adults with relative memory impairment (OD) adults.

\section{Recognition False Alarm Rate}

A 3 (group: Young, Older-Control, Older adults with relative cognitive impairment) x 2 (gender: female, male) x 3 (Stimulus: L word, X-word, new-word) mixed factorial ANOVA revealed a significant main effect of Group, $F_{2,54}=5.56 ; P=0.006$, partial $\mathrm{h}^{2}=$ 0.17 , with lower overall FA rate in Younger adults $(\mathrm{M} \pm \mathrm{SE}=24.85 \pm 2.07)$ when compared with both Older- Controls $(\mathrm{M} \pm \mathrm{SE}=35.44 \pm 2.95)(P=0.015)$. The difference between Younger adults and Older relatively impaired adults $(\mathrm{M} \pm \mathrm{SE}=35.44 \pm 3.48)$ was not statistically significant $(P=0.06)$, nor was there a statistically significant difference between Older-Controls and Older relatively impaired adults. There was also a main effect of Stimulus, (sphericity was violated, therefore Greenhouse-Geisser corrected values were used), $F_{1.32,71.18}=10.40 ; P=0.001$, partial $\mathrm{h}^{2}=0.16$, with lower FA rate for New words $(\mathrm{M} \pm \mathrm{SE}=22.04 \pm 2.35)$ compared with $\mathrm{X}$-words $(\mathrm{M} \pm \mathrm{SE}=42.05 \pm 3.56)(P=1.97 \mathrm{E}-9)$. The 
Group x Stimulus nor the Group x Stimulus x Gender interaction effects were not significant, $F_{2.6,71.18}=1.71 ; P=0.18 ; F_{2.6,71.18}=1.32 ; P=0.28$ (see Supplementary Figure 1b).

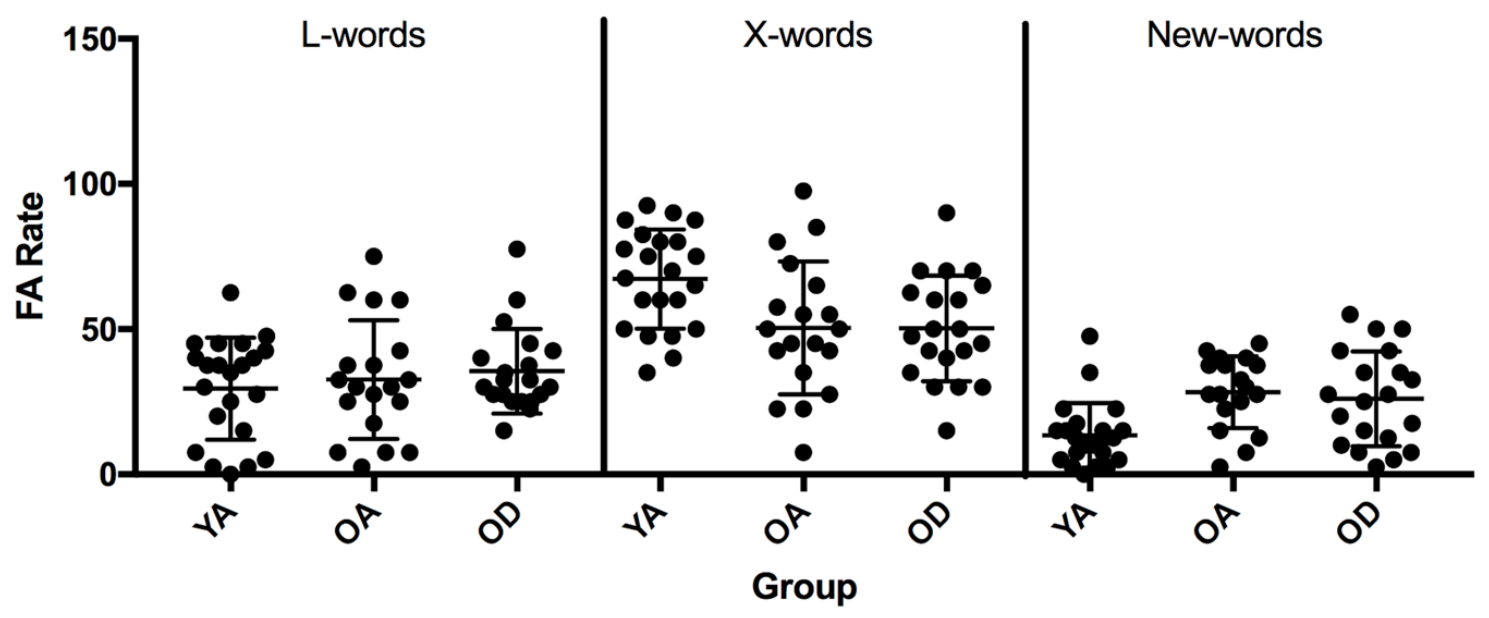

Figure 1B: Scatter plots (with mean and IQR) showing recognition memory accuracy (False Alarm Rate) for L-words, X-words and New words for Young (YA), Older control $(\mathrm{OA})$ and Older adults with relative memory impairment (OD) adults. 
3.Lateralisation of waveform components and relationship to behavioural measures

\begin{tabular}{|c|c|c|c|c|}
\hline & & & Accuracy & $\begin{array}{l}\text { Reaction } \\
\text { Time }\end{array}$ \\
\hline & & & $\mathrm{t}, \mathrm{p}$ & $\mathrm{t}, \mathrm{p}$ \\
\hline \multirow[t]{6}{*}{ YA } & New Word & Posterior LPP & $0.14,0.59$ & $0.54,0.017$ \\
\hline & & Frontal P2 & $-0.04,0.87$ & $0.14,0.58$ \\
\hline & L-Word & Posterior LPP & $-0.17,0.49$ & $0.15,0.53$ \\
\hline & & Frontal P2 & $-0.37,0.12$ & $-0.22,0.36$ \\
\hline & X-word & Posterior LPP & $0.04,0.87$ & $-0.18,0.46$ \\
\hline & & Frontal P2 & $-0.1,0.67$ & $-0.41,0.08$ \\
\hline \multirow[t]{6}{*}{$\mathrm{OA}$} & New Word & Posterior LPP & $0.013,0.96$ & $0.02,0.93$ \\
\hline & & Frontal P2 & $-0.45,0.06$ & $0.36,0.14$ \\
\hline & L-Word & Posterior LPP & $-0.25,0.32$ & $0.17,0.49$ \\
\hline & & Frontal P2 & $-0.09,0.72$ & $0.31,0.21$ \\
\hline & X-word & Posterior LPP & $-0.25,0.32$ & $-0.13,0.6$ \\
\hline & & Frontal P2 & $-0.09,0.71$ & $0.29,0.35$ \\
\hline \multirow[t]{6}{*}{ OD } & New Word & Posterior LPP & $-0.37,0.12$ & $0.02,0.94$ \\
\hline & & Frontal P2 & $0.04,0.87$ & $0.16,0.51$ \\
\hline & L-Word & Posterior LPP & $0.04,0.62$ & $-0.16,0.24$ \\
\hline & & Frontal P2 & $0.06,0.79$ & $0.28,0.24$ \\
\hline & X-word & Posterior LPP & $-0.12,0.62$ & $-0.16,0.51$ \\
\hline & & Frontal P2 & $-0.09,0.68$ & $0.02,0.93$ \\
\hline
\end{tabular}

Supplementary Table 1: Correlational analysis between Lateralisation Index (of LPP (Late Posterior Positivity) and frontal P200 mean amplitude in left and right hemispheres) and behavioural measures (accuracy and reaction time) for each group (YA: younger adults; OA older control adults; OD older adults with relative memory impairment) during recognition. 